HID 40 (2013)

\title{
LAS SALINAS DE ATIENZA, MEDINACELI Y MOLINA DE ARAGÓN EN LA BAJA EDAD MEDIA: PROPIEDAD, COMERCIO Y FISCALIDAD $^{1}$
}

\author{
THE SALTWORKS OF ATIENZA, MEDINACELI AND MOLINA DE \\ ARAGÓN IN THE LATE MIDDLE AGES: PROPERTY, TRADE AND \\ TAXATION
}

\author{
Pablo Ortego Rico \\ Universidad Complutense de Madrid \\ pabloortego@gmail.com
}

RESUMEN: Estudio global de las salinas del obispado de Sigüenza entre los siglos XIII-XV, atendiendo a aspectos económicos y políticos como la evolución del régimen de propiedad en el contexto de formación y consolidación del monopolio regio sobre su explotación; el sistema de gestión y la regulación ordenancista que habilitó la fijación de precios, el establecimiento de áreas de venta exclusiva para la sal producida, y la creación de formas de control del contrabando; y el rendimiento fiscal para la Corona.

Palabras ClaVe: Salinas, fiscalidad real, comercio. Atienza, Medinaceli, Molina de Aragón, Castilla, siglos XIII-XV.

ABSTRACT: Global study of the saltworks in the bishopric of Sigüenza between $\mathrm{XIII}{ }^{\text {th }}$ and $\mathrm{XV}^{\text {th }}$ centuries based on economic and political aspects such as the evolution of the property in the context of formation and consolidation of the royal monopoly over their exploitation; the management system and the prescriptive regulation that enabled price fixation, the establishment of exclusive sale areas for the salt produced, and the creation of forms of smuggling control; and the financial performance for the Crown.

KEYwords: Saltworks, royal taxation, trade, Atienza, Medinaceli, Molina de Aragón, Castile, Thirteenth-Fifteenth centuries.

1. Abreviaturas utilizadas: $\mathrm{AGS}=$ Archivo General de Simancas; $\mathrm{AHN}=$ Archivo Histórico Nacional; $\mathrm{CCA}=$ Cámara de Castilla; Ced. = Libros de Cédulas; CMC, 1 a ép. = Contaduría Mayor de Cuentas, Primera Época; CSA = Cuaderno de las salinas de Atienza de 1447; Div. = Diversos; doc. = documento; $\mathrm{EMR}=$ Escribanía Mayor de Rentas; MP = Mercedes y Privilegios; mrs. = maravedíes; $\mathrm{PR}=$ Patronato Real; RAH = Biblioteca de la Real Academia de la Historia; RGS = Registro General del Sello; SNAHN $=$ Sección Nobleza del Archivo Histórico Nacional; SyC = Colección Salazar y Castro. 


\section{Las explotaciones salineras en el obispado de Sigüenza}

La explotación salinera en el valle del río Salado y otras áreas de la actual provincia de Guadalajara que formaban parte del obispado de Sigüenza en la Edad Media caracterizadas por el afloramiento de sedimentos salinos cuenta con una tradición secular, que probablemente arranca de los tiempos protohistóricos ${ }^{2}$. En este sentido, distintos estudios llevados a cabo desde el punto de vista de la arqueología del paisaje ${ }^{3}$ han puesto de manifiesto el papel que pudo haber desempeñado la extracción de sal en la estructuración del poblamiento de la zona desde la época romana hasta los momentos anteriores a la conquista cristiana llevada a cabo en el siglo XII ${ }^{4}$. Por otra parte, no hay que olvidar que la explotación de las salinas de las comarcas de Atienza, Sigüenza, Medinaceli o Molina de Aragón actuó desde el siglo XIII como motor de desarrollo de unas áreas deprimidas tanto a nivel demográfico como económico ${ }^{5}$, al tiempo que se convertía en una fuente de recursos fiscales para la Monarquía castellana que llegó a alcanzar cierta relevancia en el contexto hacendístico bajomedieval apoyada en unos elevados niveles de producción, tal y como explicitan los datos fiscales conservados desde fines del siglo XIII ${ }^{6}$. De esta forma, el objetivo de este trabajo no es otro que profundizar, desde una perspectiva integradora, en diversos aspectos relacionados con el régimen de propiedad, la producción y comercio de la sal en el área de estudio delimitada como forma de aproximación no solo a una realidad de carácter económico, sino también a las implicaciones que en el ámbito político-fiscal tuvo el

2. J. TALAVERA COSTA. "La sal en la comarca de la Sigüenza arévaca: ¿Riqueza naturalriqueza social?", en N.E. MORÈRE MOLINERO. (coord.) Las salinas y la sal de interior en la historia: economía, medio ambiente y sociedad, Madrid, Universidad Rey Juan Carlos-Dykinson, 2007, vol. 1, pp. 241-262.

3. A. MALPICA CUELLO. "Análisis de la salinas medievales desde la arqueología del paisaje", en N.E. MORÈRE MOLINERO. (coord.) Las salinas y la sal..., vol. 1, pp. 469-499.

4. A. MALPICA CUELLO, G. GARCÍA-CONTRERAS RUIZ. "Asentamientos y explotación de la sal en el valle del Salado y la zona de Sigüenza en época altomedieval”, En la España Medieval, 32 (2009), pp. 295-324. G. GARCÍA-CONTRERAS RUIZ. "Territorio y explotación de la sal en el valle del Salado (Guadalajara) en época andalusí”, @rqueología y Territorio, 6 (2009), pp. 211-224. N.E. MORÈRE MOLINERO. "L'exploitation romaine du sel dans la region de Sigüenza”, Gerión, 3 (1991), pp. 223-236; id., "La sal en el desarrollo histórico de Sigüenza. Los primeros siglos", en N.E. MORÈRE MOLINERO. (coord.) Las salinas y la sal..., vol. 1, pp. 3-31.

5. M.E. CORTÉS RUIZ. Articulación jurisdiccional y estructura socioeconómica en la comarca de Molina de Aragón a lo largo de la baja Edad Media. Madrid, Universidad Complutense de Madrid, 2003.

6. Sobre la fiscalidad asociada a la sal en Castilla ver los trabajos clásicos de C. ESPEJO. "La renta de las salinas hasta la muerte de Felipe II", Revista de Archivos, Bibliotecas y museos, 38 (1918), pp. 47-63 y 220-233; 39 (1918), pp. 37-53; y 40 (1919), pp. 91-114. R. PASTOR DE TOGNERI. "La sal en Castilla y León. Un problema de alimentación y del trabajo y una política físcal (siglos X-XIII)", Cuadernos de Historia de España, XXXVII-XXXVIII (1963), pp. 42-85. M.Á. LADERO QUESADA. "La renta de la sal en la Corona de Castilla (Siglos XIII-XVI)", en Homenaje al profesor Juan Torres Fontes, Murcia, Universidad de Murcia, 1987, vol. I, pp. 821-838. 
aprovechamiento de un recurso natural relativamente escaso y concentrado, pero fundamental para el consumo humano y animal, como la sal ${ }^{7}$.

1.1. Salinas y propietarios en el marco de construcción del ius regalium sobre la explotación de la sal (siglos XIII-XV)

Las primeras referencias en las fuentes cristianas relativas al aprovechamiento salinero en la zona del obispado seguntino datan del siglo XII. Ya en dos concesiones regias realizadas en julio y noviembre de 1124 -es decir, en el momento inmediatamente posterior a la conquista de la zona llevada a cabo por Alfonso VIIse menciona la cesión en favor de la iglesia de Sigüenza de las salinas incluidas en su término, así como de ciertos derechos asociados a su producción, como la décima de la sal, lo cual parece indicar -a pesar del formulismo habitual presente en este tipo de fuentes- que los recursos salinos de este territorio ya eran explotados previamente y se consideraban de suficiente entidad como para figurar de forma explícita en ambos privilegios ${ }^{8}$. Dejando a un lado esta alusión, casi un siglo después el testamento de Alfonso VIII (1204) incluye las salinas de Atienza y Medinaceli -junto a otras como las de Belinchón, Rosío o Espartinas-, dentro de los bienes de la Corona señalados como garantía para el pago de ciertas deudas regias, lo cual indica que la regalía sobre esta fuente de riqueza ya era efectiva en ese momento y proporcionaba importantes recursos a la Monarquía castellana ${ }^{9}$. El ejercicio del dominio eminente de la Corona sobre estas explotaciones vuelve a quedar explicitado en diversos privilegios de donación otorgados desde fines del siglo XII a partir de los cuales los monarcas castellanos cedieron a ciertas instituciones religiosas rentas en "juro de heredad" con cargo al rendimiento de las salinas atencinas que, en muchos casos, seguían vigentes a fines de la Edad Media. Ya en abril de 1192 Alfonso VIII donaba al monasterio de las Huelgas de Burgos 40 áureos en las salinas de Atienza a cambio de la entrega de la villa de Castro Urdiales ${ }^{10}$. En noviembre de 1211 el mismo monarca realizaba una nueva concesión con cargo a las salinas atencinas en favor del Hospital del Rey de Burgos ${ }^{11}$, y en

7. El estudio de las salinas medievales de la Península Ibérica ha alcanzado una renovación significativa en los últimos años. Sin ánimo de ser exhaustivo ver los siguientes trabajos: N.E. MORĖRE MOLINERO. (coord.) Las salinas y la sal de interior..; A. MALPICA CUELLO, J.A. ANTONIO GONZÁLEZ ALCANTUD. (coords.) La sal, del gusto alimentario al arrendamiento de salinas, Granada, Junta de Andalucía-Consejería de Cultura, 1997.

8. T. MINGUELLA Y ARNEDO. Historia de la diócesis de Sigüenza y sus obispos, Madrid, Imprenta de la Revista de Archivos, Bibliotecas y Museos, 1912, vol. 1, docs. II y III, pp. 348-349. Ambos documentos son analizados por A. MALPICA CUELLO, G. GARCÍA-CONTRERAS RUIZ. "Asentamientos y explotación...", pp. 302-303. Ver también J.A. MARTÍNEZ GÓMEZ-GORDO. "Donaciones reales a la iglesia seguntina con los diezmos de las Salinas de Imón", Anales seguntinos, 22 (2006), pp. 7-12.

9. J. GONZÁLEZ GONZÁLEZ. El Reino de Castilla en la época de Alfonso VIII, Madrid, CSIC, 1960, vol. III, doc. 769, p. 345.

10. RAH, SyC, O-22, f. 108.

11. RAH, SyC, O-17, ff. 536-537. En el mismo documento cedía también al Hospital el dominio sobre Tordesillas. 
junio de 1214 entregaba ciertas cargas de sal de las salinas de Medinaceli a fray Cipriano, abad del monasterio de Nuestra Señora de la Vid ${ }^{12}$. Por su parte, Fernando III concedía el 3 de julio de 1231 al mencionado monasterio de las Huelgas 20 cahíces de sal en las salinas de Atienza y ordenaba a sus arrendadores pagar dicha cantidad, mención que certifica el funcionamiento del régimen de gestión indirecto de las explotaciones salineras mediante su arrendamiento desde al menos los años iniciales del siglo XIII ${ }^{13}$. Finalmente, en noviembre 1269 Alfonso X otorgaba al convento de Santo Domingo de Madrid 8.000 cahíces de sal anuales pagaderos con cargo a las mias salinas de Atiença ${ }^{14}$, en un momento marcado por la reafirmación teórica de la capacidad de la Monarquía para aprovecharse de los recursos salinos como parte integrante del ius regalium o conjunto de derechos imprescriptibles asociados a la soberanía regia ${ }^{15}$, según aparece consignado en la Tercera Partida alfonsí1 ${ }^{16}$, y posteriormente en textos como el ordenamiento de la sal de 1338 o el Ordenamiento de Alcalá de $1348^{17}$.

Por otra parte, la relevancia de las salinas como recurso fiscal queda reflejada de forma clara en el libro de rentas reales de 1292, en el cual aparecen consignados los primeros datos cuantitativos relativos a estas explotaciones, además de la mención a las salinas de Sant Felizes -actual Saelices de la Sal- situadas a medio camino entre Sigüenza y Molina de Aragón ${ }^{18}$. En aquel momento las de Atienza rendían a la Corona 100.000 mrs. "de la guerra" y suponían el 36,3 \% del total de los ingresos percibidos por este concepto - de forma que a fines del siglo XIII ya eran las más importantes en términos fiscales del antiguo Reino de Castilla-, mientras que las de Medinaceli fueron franqueadas en 1289 por lo que no se conservan datos fisca-

12. RAH, SyC, O-22, f, 136v.

13. “...do Deo et monasterio Sancte Marie regalis de Burgis, conuentui monialium ibidem Deo seuiencium, uiginti kaficios de sale in salinis meis de Atencia annuatim percipiendos et iure hereditario habendos et irreuocabiliter possidendos. Et mando arrendatoribus quicumque salinas meas tenuerint arrendatas quod singulis annis respondeant cum predictis uiginti kaficios de sale hominibus predicti monasterii quos pro eisdem abbatissa iusserint uel conuentus”. J. GONZÁLEZ GONZÁLEZ. Reinado y diplomas de Fernando III. Vol. II. Diplomas (1217-1232), Córdoba, Publicaciones del Monte de Piedad y Caja de Ahorros de Córdoba, 1983, doc. 349, p. 403.

14. M.T. HERRERA. Documentos de Alfonso X dirigidos a Castilla la Nueva, Madison, Hispanic Seminary of Medieval Studies, 1999. Carta de donación dada en Madrid el 8 de noviembre de 1269. Publicada en REAL ACADEMIA ESPAÑOLA: Banco de datos (CORDE) [en línea]. Corpus diacrónico del español. http://www.rae.es [Fecha de la consulta: 26/09/2013].

15. Sobre la consideración de las salinas como regalía ver M.Á. LADERO QUESADA. Fiscalidad y poder real en Castilla (1252-1369), Madrid, Real Academia de la Historia, 2011 [2 $2^{\mathrm{a}}$ ed.], pp. 86-87.

16. Partida III, Tit., 28, ley 11. Las Siete Partidas del rey don Alfonso el Sabio, Madrid, Imprenta Real, 1807, p. 713.

17. "Todas las aguas, e poços salados que son para facer sal e todas las rentas dellas, rindan al Rey, salvo las que dio el Rey por previllejo, o las ganó alguno por tiempo en la manera que devia”. Tit. XXXII. Ley XLVIII. I.J. ASSO Y DEL RÍO, M. DE MANUEL Y RODRÍGUEZ. El ordenamiento de leyes que D. Alfonso XI hizo en las Cortes de Alcalá de Henares el año de mil trescientos y quarenta y ocho, Madrid, Joaquín Ibarra, 1774, pp. 134-135.

18. Sobre estas salinas ver E. GARCÍA-SOTO MATEOS, S. FERRERO ROS. "Excavaciones en las salinas de San Juan: Saelices de La Sal, Guadalajara”, Boletín de la Asociación de Amigos del Museo de Guadalajara, 1 (2006), pp. 81-112. 
les para esta época ${ }^{19}$. Por su parte, el ordenamiento relativo a la sal promulgado por Alfonso XI en 1338 amplía la nómina de salinas del obispado seguntino, incorporando a las de Atienza, Saelices y Medinaceli las de Molina [de Aragón] y Almalla, estas últimas ya mencionadas junto a las de Traid en el fuero concedido por el conde Manrique de Lara a Molina en $1142^{20}$ y explotadas casi con total seguridad en la época musulmana a tenor del nombre que tenían asignado, que no es sino una derivación de la propia palabra sal en árabe $(a l-m i l h)^{21}$. En este sentido, hay que tener en cuenta que a pesar de la denominación genérica que recibían habitualmente

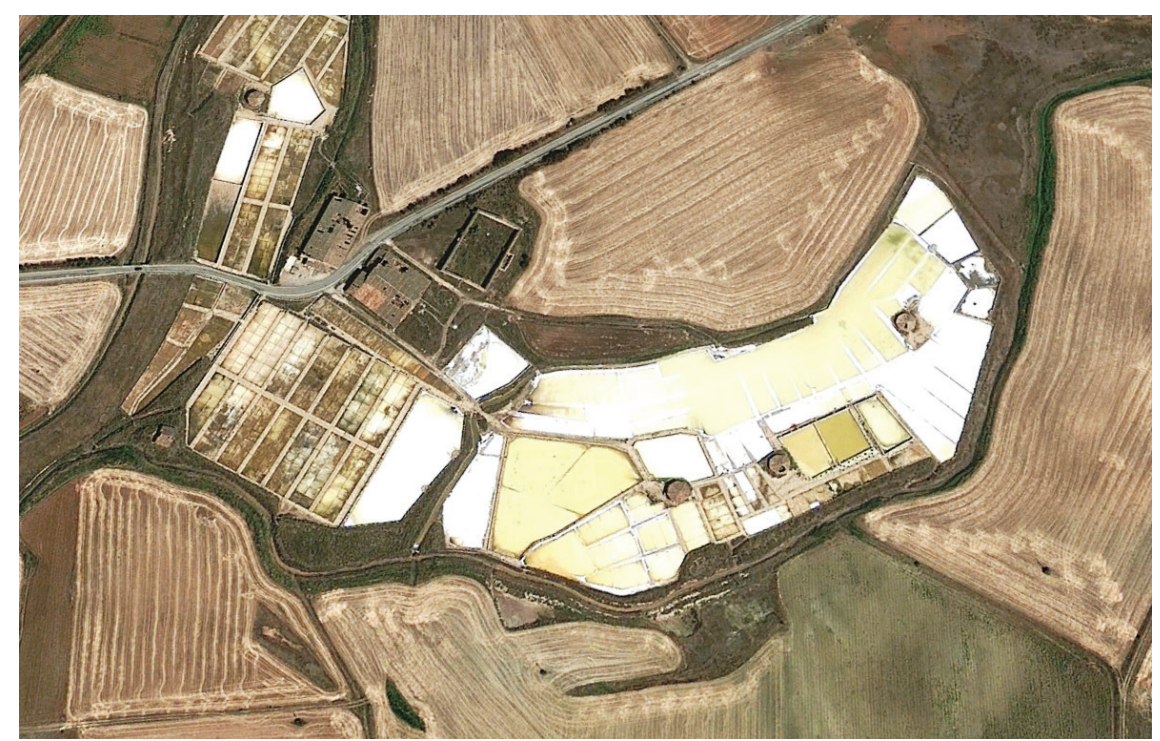

Ilustración 1. Vista aérea de las salinas de Imón en su estado actual

en la documentación bajomedieval las salinas de la zona norte de la actual provincia de Guadalajara, cada área de producción contaba con varias explotaciones diferenciadas. Por ejemplo, dentro del grupo de salinas de la comarca de Atienza destacaban fundamentalmente las de La Olmeda -también llamadas de Bonilla-, ubicadas en las inmediaciones de Jadraque, y las de Imón, ya mencionadas en el Libro de la caza de don Juan Manuel (1337-1348)22. Estas últimas se encontraban

19. F.J. HERNÁNDEZ. Las rentas del rey. Sociedad y fisco en el reino castellano del siglo XIII, Madrid, Fundación Ramón Areces, 1994, vol. I, pp. CXXIX y 119-121.

20. "Do a uos fuero para siempre que todos los vezinos de Molina caualleros et clérigos y jodios reciban sendos dafizes de sal cada anno et den en precio destos cafizes sendos mencales. Et que recibidos estos cafizes en trayt o en Almallay con uestro escriuano et mio et quien en otra mientre la tomare peche cient marauedis". M. SANCHO IZQUIERDO. El Fuero de Molina de Aragón, Madrid, Victoriano Suarez, 1916, p. 65.

21. E. GONZÁLEZ CRESPO. Colección documental de Alfonso XI, Madrid, Universidad Complutense de Madrid, 1985, doc. 257, pp. 434-439.

22. "Çerca de las salinas de Aymon, viene vn arroyo en que ha buenas anades para caçar con falcones. El arroyo de Rio Salido nasçe en el aldea que a nonbre Rio Salido, et fasta que llega al arroyo 
situadas a unos 12 kilómetros al este de Atienza y aparecen descritas en una nota marginal incluida en un documento de 1477 como las mejores de todas e donde se faze la sal colorada ${ }^{23}$. No obstante, existían otras muchas explotaciones de menor entidad en localidades situadas en las inmediaciones de Atienza y Sigüenza, como Carabias, Paredes, Rienda, Romanillos, o Santamera/Gormellón ${ }^{24}$. Lo mismo cabe señalar, como se verá a continuación, en relación a las explotaciones de la comarca de Medinaceli y de Molina de Aragón.

Las afirmaciones teóricas contenidas en los ordenamientos legales relativas al ejercicio de la regalía sobre la sal no impidieron que en diversos momentos los reyes castellanos considerasen como objeto graciable la cesión del usufructo o el dominio útil de algunas explotaciones -aunque nunca la propiedad eminente o plena- en favor de instituciones religiosas y particulares, una vez culminado durante el reinado efectivo de Alfonso XI el proceso de consolidación de la soberanía regia sobre la explotación de la sal. Ello permite explicar la aparición durante la época Trastámara de multitud de propietarios particulares de salinas, cuyos derechos -reconocidos inicialmente en los privilegios reales de concesión-, quedaron apuntalados en algunos casos tras su incorporación al corpus de legislación tributaria ya maduro en época de Juan II. Así, según el cuaderno de arrendamiento de las salinas de Atienza dado en Arévalo en junio de 1447, el conde de Medinaceli poseía de forma legítima las salinas de Medinaceli y de Saelices ${ }^{25}$, dominio cuyo origen se encuentra en el documento por el cual Enrique II donaba en julio de 1368 a Bernal de Bearne dicho condado ${ }^{26}$. Estas salinas, embargadas por Alfonso XI para la Corona en 1338, habían sido explotadas poco antes por más de una decena de particulares e instituciones religiosas, lo cual certifica que, a pesar de las formulaciones doctrinales recogidas en las Partidas, en muchos casos el monopolio regio sobre la sal no había tenido una aplicación completa antes del reinado de Alfonso XI. Por ejemplo, en el testamento otorgado por el obispo de Sigüenza fray Alonso Pérez de Zamora en 1332 se mencionan -junto a sus propietarios- las

de las Salliniellas, a en el anades a logares et buen lugar para las caçar con falcones. Et en el arroyo de las Salinas fasta que entra en las salinas de Boniella, a muchas anades et buen lugar para las caçar con falcones". JUAN MANUEL. Libro de la caza, J.M. Blecua (ed.), Madrid, Gredos, 1981, p. 595.

23. AGS, EMR, leg. 23, f. 161.

24. A. LÓPEZ GÓMEZ. "Salinas de la comarca de Imón (Guadalajara)", Estudios Geográficos, vol. $31, \mathrm{n}^{\circ} 120$ (1970), pp. 371-394.

25. M.Á. LADERO QUESADA. Legislación hacendística de la corona de Castilla en la Baja Edad Media, Madrid, Real Academia de la Historia, 1999, Cuaderno de las salinas de Atienza de 1447 [en adelante CSA], ley 19, p. 422. En las salinas de Saelices también se mencionan como propietarios a los herederos del Adelantado Mayor Gómez Manrique, fallecido en 1411. Sobre Gómez Manrique ver A. FRANCO SILVA. "La fortuna del Adelantado Mayor de Castilla Gómez Manrique", en id., La fortuna y el poder. Estudios sobre las bases económicas de la aristocracia castellana (S.XIV-XV), Cádiz, Universidad de Cádiz, Servicio de Publicaciones, 1996. pp. 355-378. No obstante, las salinas de Saelices no se mencionan entre los bienes del Adelantado, según la relación aportada por A. Franco.

26. En el término de Medinaceli entraban también las salinas de Saelices y Almalla. M.L. PARDO RODRÍGUEZ. Documentación del condado de Medinaceli (1368-1454), Soria, Diputación de Soria, 1993, doc. 1, p. 129. 
siguientes salinas, todas ellas pertenecientes al grupo de Medinaceli y colindantes con las que allí tenía el prelado ${ }^{27}$ :

- Salinas que dicen de la sacristanía de la orden del monasterio de Huerta [...] de las que dizen de la Soga, situadas en Medinaceli en el pago de suso, otorgadas por el obispo al cabildo seguntino. Al parecer, habían sido compradas previamente a Pedro Martínez de Jarava, abad de Santa Coloma

- Salinas de los clérigos del cabildo de Medinaceli

- Salinas de la abadía de Santa María de Medinaceli

- Salinas de la iglesia de San Gil de Medinaceli

- Salinas de la iglesia de San Martín de Medinaceli

- Salinas de San Andrés de Medinaceli

- Salinas de Pedro Pérez, hijo de doña Juana

- Salinas de Martín Fernández, sobrino de Pedro Pérez

- Salinas de Miguel Sánchez

- Salinas de Sancho González, hijo de Gonzalo Martínez

- $\quad$ Salinas de Domingo Pérez de Per Yeñeguez

- Salinas de Rabí Yuda

- $\quad$ Salinas de doña Rama y de su hijo Gil Martínez

Esta diversidad de propietarios provocaba en ocasiones cierta confusión a la hora de determinar la titularidad de determinadas explotaciones, como se observa al analizar la documentación relativa a las salinas de Almalla y Saelices, que eran las más alejadas de la villa de Medinaceli. Por una parte, sabemos que antes del embargo de las salinas decretado por Alfonso XI en 1338 las de Almalla habían pertenecido al monasterio de Santa María de Ovila, que recibió cierta cantidad de sal en compensación por su toma para la Corona ${ }^{28}$. Más adelante, el 17 de junio de 1370 el conde de Medinaceli ratificaba a Juan Duque, vasallo del rey, en la posesión de las salinas de Saelices y Almalla, donadas previamente por Enrique II como merced en juro de heredad ${ }^{29}$. Por otro lado, el 26 de junio de 1383 Luis Martínez de Aguilera, hijo de Juan Martínez de Aguilera y vecino de Medinaceli, llegaba a un acuerdo económico con Mayor de Vera, monja del monasterio de Santa María de Buenafuente, por la donación que esta última le había realizado de toda la parte e derecho que tenía en las salinas de Almalla que son en la Loma en término de Medinaceli ${ }^{30}$. ¿A quién pertenecían entonces las salinas? Lo más probable es que, a pesar de la donación realizada, ciertos particulares tuviesen permitida la

27. T. MINGUELLA Y ARNEDO. Historia..., vol. 2, doc. LXXIX, p. 502.

28. M.L. PARDO RODRÍGUEZ. Documentación..., docs. 17, 66 y 67, pp. 157-158, 207-208 y 234-235

29. Ibid., docs. 2 y 3 , pp. 131-135.

30. En el acuerdo se comprometía a entregar anualmente antes de San Miguel mientras viviese doña Mayor 50 "medias" [sic] de sal de la medida usual, un cerdo, una arroba de lana merina y media arroba de queso, todo ello puesto en el monasterio de Santa María de Buenafuente. Asimismo, en caso de que Luis Martínez falleciese antes que doña Mayor el derecho a la explotación de la parte de las salinas revertiría en esta última. Ibid., doc. 89, pp. 237-239. 
explotación de algunos pozos mediando algún tipo de cesión o contrato, aunque la documentación no permite profundizar en esta cuestión.

En cuanto a las salinas de Saelices, de nuevo a fines de la década de 1380 formaban parte de las propiedades de la casa condal de Medinaceli, tal y como certifica el poder otorgado por la condesa Isabel de la Cerda el 1 de marzo de 1388 en favor de su alcalde mayor Velasco Martínez para que tomase posesión en su nombre de estas explotaciones por quanto son mías e me pertenesçen ${ }^{31}$. No obstante, su disfrute fue objeto de disputa a raíz de su donación por Enrique III en favor del Adelantado Mayor de Castilla Gómez Manrique en algún momento de su minoría (1390-1393). Según notificaba el rey el 4 de septiembre de 1394 al conde don Gastón de la Cerda, el Adelantado había denunciado la negativa del primero a entregarle las salinas de Saelices, de forma que, para evitar escándalos, se encomendaba a los doctores Vicente Arias y Diego Martínez determinar el derecho de las partes, al tiempo que se ordenaba tomar para la Corona las salinas mientras se sustanciaba el pleito ${ }^{32}$. Don Gastón respondió el 26 de octubre de 1394 al requerimiento regio defendiendo su derecho previo al disfrute de estas salinas en virtud de la merced otorgada por Enrique II a su padre don Bernal de Bearne y recordando la revocación de las mercedes concedidas durante la minoría de Enrique III -entre ellas la de las salinas de Saelices realizada en favor del Adelantado- ordenada una vez que el rey tomó de sí el regimiento del reyno ${ }^{33}$. La cuestión se complicó todavía más después de que el mariscal García González de Herrera, heredero de Fernán Duque, hijo de Juan Duque -al cual como vimos había otorgado Enrique II las salinas en juro de heredad, merced reconocida por el I conde de Medinaceli-, solicitara el amparo regio. Por lo tanto, ahora era necesario decidir entre el derecho de tres propietarios aparentemente legítimos, tarea encomendada por Enrique III al arzobispo de Toledo don Pedro Tenorio, que renunció a sustanciar el pleito por quanto era enfermo e ocupado de otros negoçios. El 30 de abril de 1395 el rey ponía el caso en manos de una comisión formada por el obispo de Cuenca, Alfonso Rodríguez y Diego Hurtado, oidores de su Audiencia, ante los cuales los afectados hubieron de presentar los títulos que legitimaban su posición y los alegatos que considerasen oportunos en defensa de su derecho ${ }^{34}$. Finalmente, el pleito se resolvió gracias a una carta real dada antes de 1404 en la cual el rey mandaba defender al conde de Medinaceli en la posesión de las salinas de Saelices y anular la merced otorgada al Adelantado, aunque compensaba

31. Ibid., doc. 95, pp. 244-245. La toma de posesión fue realizada al día siguiente. Ibid., doc. 96, p. 245.

32. Ibid., doc. 112, p. 266. El 17 de marzo de 1396 Enrique III mandaba a los concejos de Bembibre, Castrocalvón y Valdería dar la tenencia y posesión de estos lugares al Adelantado Mayor Gómez Manrique hasta que el conde de Medinaceli quitase el embargo puesto en las salinas de Saelices. Ibid., doc. 118, pp. 273-274. El 19 de mayo de 1396 se volvía a autorizar, tras la queja planteada por el conde de Medinaceli, la posesión de este último sobre las salinas de Saelices hasta que fuese resuelto el pleito con Gómez Manrique. Ibid., doc. 119, pp. 274-275.

33. Ibid., doc. 113 , pp. 267-268.

34. Ibid., doc. 116, pp. 270-271. El 8 de mayo de 1395 la comisión mandaba comparecer al conde de Medinaceli. Ibid., doc. 117, pp. 271-272. 
a este con una merced anual de 20.000 mrs. pagadera con cargo a la cantidad que cobraba el conde en concepto de "tierra" de la Real Hacienda ${ }^{35}$. En cualquier caso, lo cierto es que desde comienzos del siglo XV tanto las salinas de Saelices como las de Medinaceli quedaron al margen del arrendamiento de las salinas de Atienza, Molina y otras situadas en el obispado de Sigüenza, tal y como se observa en el contrato concertado entre la Corona, por un lado, y Juan Núñez de Guadalajara y Juan Martínez de Lana, por otro, para la gestión de estas últimas durante el período $1415-1418^{36}$.

Por su parte, las salinas de Terzaga, situadas en el término de Molina de Aragón, pertenecieron a diversos propietarios desde el siglo XIII. Ya el 27 de marzo de 1272 el infante Alfonso, señor de Molina, autorizaba al monasterio de Huerta la extracción de sal en las mencionadas salinas ${ }^{37}$, que en la segunda mitad del siglo XIV pertenecían a Adán García de Vargas, tal y como constata el situado de 3.000 mrs. de la "moneda vieja" pagaderos con cargo a las salinas de Atienza que sus herederos tenían reconocido en 1447 como compensación a su toma por la Corona ${ }^{38}$. Por otro lado, sabemos que el 2 de enero de 1385 Useda López de Limán, vecina de Molina y viuda de Adán García de Vargas, vendía en nombre de sus hijos Rodrigo, Jimeno y Sancho López, como legítimos herederos, a doña Aldonza de Ayala, mujer del camarero mayor del rey Pedro González de Mendoza, las salinas de Terzaga por 12.000 mrs. que le fueron entregados por don Farache, hijo de don Yahya, moro vecino de Molina. ¿A qué obedece entonces el pago compensatorio que figura en 1447 en favor de los herederos de Adán García de Vargas si realmente la Corona no llegó a recuperar el control de las salinas? Aunque carecemos de respuesta para esta cuestión, lo cierto es que en el siglo XV las salinas de Terzaga y otras situadas en el término de Molina, como las de Traid, pasaron a formar parte del patrimonio de los condes de Priego - que también disponían de las salinas de Valdeáguila, localizadas en el término de su lugar de Castilnuevo-, en cuyo poder permanecieron hasta que en octubre de 1479 el II conde Pedro Carrillo de Mendoza se las vendió al Comendador Mayor don Gutierre de Cárdenas a cambio de 15.000 mrs. en juro de heredad situados en Priego y Cañaveras y otros 20.000 mrs.de juro renunciados. Una de las cláusulas del contrato de venta suscrito establecía la obligación de cegar el pozo de Valdeáguila para que non aya memoria de salynas, aunque en caso de volver a abrirse solo Gutierre de Cárdenas podría explotarlo ${ }^{39}$. Acaso se tratase de una condición impuesta por el Comendador Mayor ante la dificultad de aprovecharse de esta sal en virtud del poder señorial ejercido por el conde de Priego sobre Castilnuevo, localidad en la cual como hemos señalado se encontraban situadas estas salinas. Por otro lado, los reyes entregaban en agosto de 1504 como merced

35. Ibid., doc. 131, p. 307.

36. AGS, EMR, leg. 1, f. 60.

37. A. BALLESTEROS BERETTA. Alfonso X el Sabio, Barcelona, Salvat, 1963, doc. 831.

38. CSA, p. 425. Ladero transcribe Tragacete, pero se refiere realmente a las salinas de Terzaga.

39. SNAHN, Priego, C. 10, docs. 30-35. 
a mosén Diego de Aguilera, comendador de Villarrubia de Santiago, el pozo de sal situado en Terzaga ${ }^{40}$.

Dejando a un lado la problemática establecida en torno al disfrute señorial de las salinas de las áreas de Medinaceli y Molina, en el siglo XV ciertas personas e instituciones también explotaban en el obispado de Sigüenza determinados pozos ya abiertos a condición de que su producción fuese vendida única y exclusivamente a los arrendadores mayores de las salinas a un precio tasado muy por debajo del precio de venta normal ( $3 \mathrm{mrs}$./fanega), medida destinada a evitar pérdidas a los arrendadores de las salinas de Atienza -que eran los únicos que podrían abrir nuevos pozos ${ }^{41}$ - susceptibles de menoscabar a corto y medio plazo su rendimiento $^{42}$. La situación quedó normalizada en algunos casos a partir de la incorporación de estas salvedades en la legislación tributaria por la cual se regía la gestión de la renta. Así, el cuaderno de arrendamiento de 1447 menciona entre los propietarios legítimos de pozos, explotados al margen de los aprovechados por los arrendadores mayores, a los siguientes particulares e instituciones, algunos de los cuales gozaban de la merced desde antiguo como hemos señalado anteriormente ${ }^{43}$ :

- El monasterio de Santa María Valbuena disponía de un pozo en las salinas de Atienza. En este caso los derechos partían de una antigua merced realizada en 1172 por Alfonso VIII al cenobio cisterciense para que gozase de 160 cahíces de sal en las salinas de Bonilla -donde se localizaba el pozo de Navafría mencionado en las fuentes de los siglos XIV y $\mathrm{XV}^{44}$ - y la exención de los hombres que trabajasen en su obtención ${ }^{45}$.

- El monasterio de Santa María de Huerta, propietario del pozo de "Alandete" o "Allendete" situado en las salinas de Medinaceli por donación de Alfonso VIII realizada en abril de 1179, confirmada por Fernando IV en 1305. No obstante, tras la toma de las salinas decretada por Alfonso XI y la oposición mostrada por el abad del monasterio, el monarca ordenaba en agosto de 1337 a los arrendadores de las salinas de Atienza y Medinaceli desembargar al abad y monasterio el pozo, pues había sido otorgado por sus antecesores para su mantenimiento, situación que se mantuvo tras el acceso al trono de Enrique $\mathrm{II}^{46}$. El privilegio de explotación seguía vigente en el siglo $\mathrm{XV}$, aunque la Corona trató de recuperar el control de esta

40. AGS, PR, leg. 59, doc. 94 .

41. CSA, ley 7, p. 419.

42. Ibid., ley 6, pp. 418-419.

43. Ibid., leyes 12 y 13 .

44. Vid. infra.

45. V.Á. ÁlVAREZ PALENZUELA. Monasterios cistercienses en Castilla (siglos XII-XIII), Valladolid, Universidad de Valladolid, 1978, p. 153. El 17 de diciembre de 1376 la infanta Leonor de Aragón, esposa del futuro Juan I de Castilla, reconocía desde Valladolid la donación del pozo de Bonilla en favor del monasterio de Valbuena. RAH, SyC, O-7, f. 111.

46. El privilegio de concesión dado en Huerta en abril de 1179 aparece inserto en una confirmación realizada por Enrique II (2 de diciembre de 1376), que a su vez también incluye la confirmación llevada a cabo por Fernando IV durante sus vistas con el rey de Aragón (25 de junio de 1305). M.L. PARDO RODRÍGUEZ. Documentación..., doc. 44, pp. 179-183. El 11 de abril de 1371 Enrique II ordenaba a los recaudadores de la sal de Medinaceli respetar la donación del pozo al abad de Santa María de Huer- 
sal autorizando - tal y como señala el cuaderno de arrendamiento de las salinas de Atienza de 1447- la cesión del pozo de Alandete a los arrendadores mayores de las salinas a cambio de que estos entregasen al abad en compensación lo que fuere sabido por buena verdad que les dan de cada año por el dicho poso. Según parece, la medida estaba relacionada con la autorización que tenía el monasterio de Huerta para vender su sal en el territorio por el cual circulaba la sal de Atienza, lo cual suponía un perjuicio para sus arrendadores ya que a bueltas de la dicha sal del dicho poso sale toda la sal de las dichas salinas de Medinaçeli en una cantidad cercana a las 25.000-30.000 fanegas ${ }^{47}$.

- Finalmente, la duquesa de Arjona doña Aldonza de Mendoza era propietaria del pozo de Portillo y de 50 cahíces toledanos (600 fanegas) en juro de heredad pagaderos con cargo a las salinas atencinas, que debían ser legados tras su muerte al monasterio de San Bartolomé de Lupiana según se establecía en su testamento $(1435)^{48}$. No obstante, la donación nunca llegó a efectuarse ${ }^{49}$ como consecuencia del pleito que interpuso su hermanastro el I marqués de Santillana Íñigo López de Mendoza, en el cual reclamaba esa sal como perteneciente a su mayorazgo ${ }^{50}$. Por ello, tras la muerte del marqués, su primogénito Diego Hurtado de Mendoza heredaba el pozo de Portillo y los 50 cahices de merced, en cuya posesión legítima se encontraba en $1468^{51}$ y siguió estando en adelante la rama principal de la familia mendocina ${ }^{52}$.

Por otra parte, pese al ideal formulado en la legislación tributaria la explotación de pozos salineros y la toma de salinas por particulares al margen de concesiones reales fue un fenómeno en alza en momentos de quiebra o cuestionamiento de la autoridad monárquica. Así se observa durante la segunda mitad del reinado de Enrique IV (1464-1474) en un contexto marcado por la crisis política y la ausencia de control hacendístico ${ }^{53}$. Que la Corona permitía tácitamente la apertura de nuevos pozos era un hecho, tal y como certifica una de las condiciones incluidas en la licitación presentada el 26 de mayo de 1466 por Mose Zaragoza, vecino de

ta. Ibid., doc. 14, pp. 154-156. Confirmación del privilegio por Juan I (4 de agosto de 1379) y Enrique III (20 de febrero de 1392) en ibid., docs. 59 y 102, pp. 193-194 y 252-253.

47. CSA, ley 13, pp. 420-421.

48. F. LAYNA SERRANO. Historia de Guadalajara y sus Mendozas en los siglos XV y XVI, Guadalajara, Aache, 1993, vol. I, pp. 315-318.

49. Así consta al dorso del original del testamento de Aldonza de Mendoza. AHN, Clero, leg. 2151, $\sin \mathrm{f}$.

50. R. PÉREZ BUSTAMANTE. El marqués de Santillana. Biografia y documentación, Santillana del Mar, Taurus, 1983, doc. 140.

51. SNAHN, Osuna, C. 1854 , doc. 1.

52. En junio de 1513, por ejemplo, Fernando el Católico solicitaba al III duque del Infantado que arrendase el pozo de sal que tenía en las salinas de Atienza a Pedro del Alcázar. RAH, SyC, M-13, f. 54.

53. El Libro de Hacienda de 1503 señala cómo "con las turbaciones acaecidas en estos reynos en tiempo del señor rey don Enrique, se ocuparon las dichas salinas por algunas personas". J.M. CARRETERO ZAMORA, D. ALONSO GARCÍA. Hacienda y negocio financiero en tiempos de Isabel la Católica: el libro de hacienda de 1503, Madrid, Editorial Complutense, 2003, p. 68. 


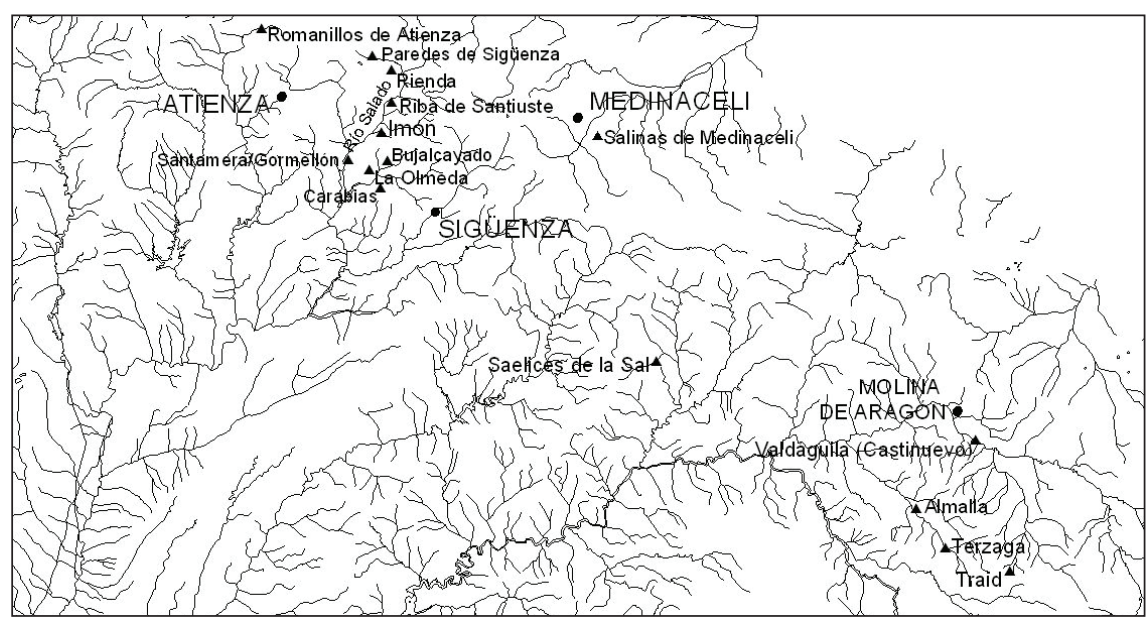

Ilustración 2. Salinas de Atienza, Medinaceli y Molina de Aragón

Segovia, para arrendar las salinas de Atienza durante el sexenio 1466-1471, según la cual se le debía aceptar a moderaçión de los contadores mayores el descuento de lo que rindiesen, en sal o maravedíes, los pozos nuevamente abiertos ${ }^{54}$. No obstante, en algunos casos la enajenación se encontraba fundamentada en la merced regia: así, entre 1466 y 1468 las salinas de Imón y Morenglos quedaron en poder del alcaide de Atienza Pedro de Almazán aunque, según parece, fueron restituidas a la Corona en 1469 una vez finalizada la crisis política de los años 1465-1468 Sin embargo, la legitimidad de su aprovechamiento probablemente fue puesta en duda posteriormente, tal y como certifica la mención al pleito abierto en junio de 1480 en el Consejo Real entre Alonso de Quintanilla y el antiguo alcaide Pedro de Almazán sobre çierta sal ${ }^{56}$.

\subsection{La salinas durante el reinado de los Reyes Católicos}

En este sentido, la política seguida por los Reyes Católicos tras su acceso al trono en 1474 supuso, como en otros ámbitos, una restauración de la legalidad y de los derechos regios, aunque tampoco conviene olvidar que la explotación de la salina más importante del área, que era la de Imón, fue cedida de por vida junto a la cercana de Anchuelo al alcaide de Atienza García Bravo en pago por su heroica actuación en el sitio y asalto a la fortaleza de Atienza durante el conflicto suceso-

54. AGS, EMR, leg. 14, f. 148.

55. AGS, MP, leg. 35. Cit. M.Á. LADERO QUESADA. "La Hacienda Real de Castilla en el siglo XV", en id., La Hacienda Real de Castilla (1369-1504), Madrid, Real Academia de la Historia, 2009 [reed. La Hacienda Real de Castilla en el siglo XV, La Laguna, Publicaciones de la Universidad, 1973], p. 175.

56. AGS, RGS, junio de 1480, f. 294. 
rio ${ }^{57}$. Para ello, una vez asegurado el control de la zona atencina, que había permanecido durante la primera parte de la contienda civil bajo el dominio del bando portugués, los monarcas encargaban el 25 de marzo de 1477 a su contino Pedro de Robles, vecino de Ávila, recibir, recaudar y apoderarse de todas las salinas de Atienza, Imón y La Olmeda, con sus "pertenencias" - a excepción de las que tenía como merced el alcaide García Bravo- y labrar y hacer labrar la sal, "encartarla" y venderla. Por otra parte, el receptor debía embargar también todos los pozos y "pertenencias" abiertos por cualesquier personas, respetando los de aquellos que tenían carta de merced librada por los contadores y asentada en los libros de la Hacienda $^{58}$.

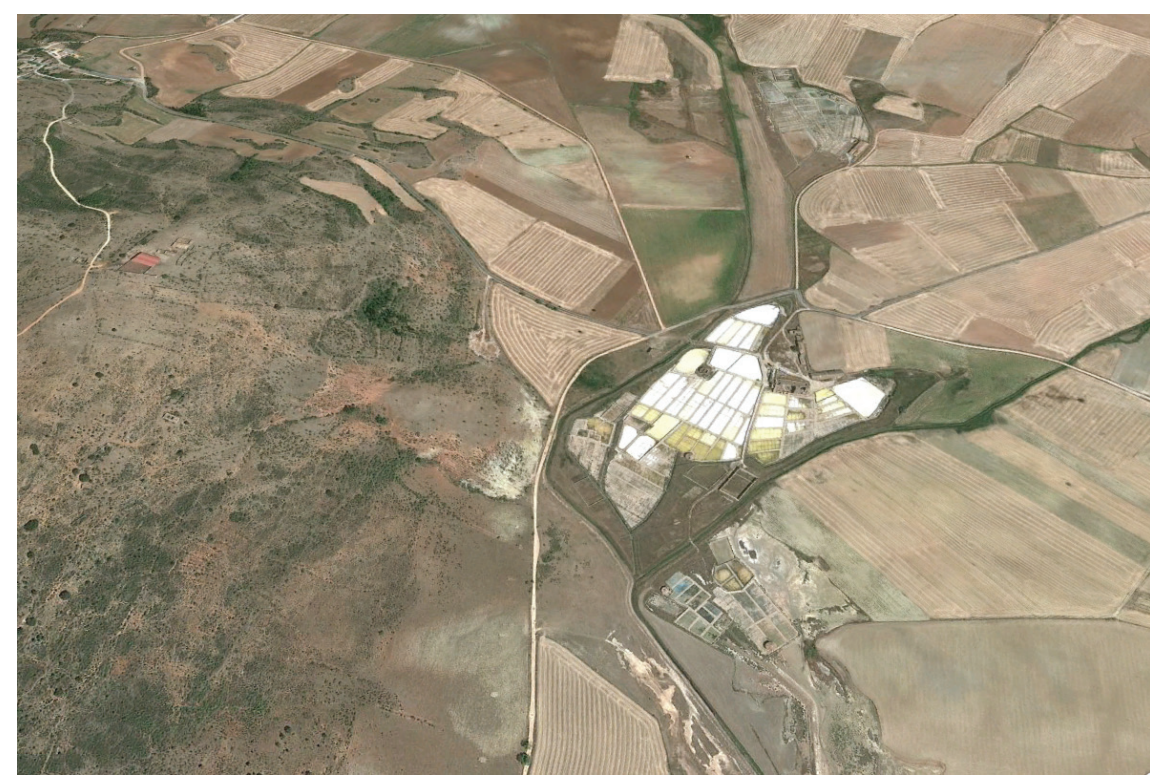

Ilustración 3. Vista aérea de las salinas de la Olmeda de Jadraque en su estado actual

57. Don Ça Caro, vecino de la ciudad de Segovia, tenía en 1490 arrendada la renta de las salinas de Atienza, Anchuelo e Imón. Estas dos últimas "las tenía e le pertenesçían e gozava el alcayde Garçía Bravo", el cual se las había arrendado en 1489 a Francisco Núñez de Talavera, vecino de Toledo, por 1.250.000 mrs. AGS, EMR, leg. 47, ff. 321-324; leg. 49, f. 362. Por su parte, Fernando de Pulgar en su Crónica menciona de forma genérica la cesión de "las salinas de Atiença, que es vna gran renta que perteneçe a los reyes de Castilla”, aunque como sabemos, esta cesión solo se refería a las de Imón. F. DE PULGAR. Crónica de los Reyes Católicos, J.M. CARRIAZO (ed). Madrid, Espasa-Calpe, 1943, vol. I, p. 226. En agosto de 1476 la reina donaba a Francisco Gudiel, su criado, un pozo de sal de los que tenía en las salinas de Atienza el antiguo alcaide Pedro de Almazán, y ordenaba al alcaide García Bravo de Lagunas entregarle "toda la sal que en el dicho pozo se fiziere". AGS, RGS, agosto de 1476, f. 554 .

58. Asiento de la carta de receptoría en AGS, EMR, leg. 23, f. 163. "Recaudo" de la receptoría dado en Madrid el 31 de marzo de 1477 en AGS, EMR, leg. 22, f. 19. En su labor fue auxiliado por el alguacil Luis Ortiz. AGS, RGS, marzo de 1489, f. 291. 
No obstante, la labor del receptor Pedro de Robles no se limitó a restaurar el control de la Corona sobre las explotaciones, sino que estuvo acompañada de la ejecución a partir de mayo de 1477 de importantes obras de acondicionamiento, principalmente en las instalaciones salineras de La Olmeda, cuya mención en las cuentas presentadas ante los contadores permite conocer mejor el funcionamiento del sistema de extracción, los medios utilizados para su mejora así como la diversidad de pozos y "pertenencias" que existían en aquel momento, embargados siguiendo el mandato regio. Una relación dada por el receptor de los pozos que se linpiaron y labraron en dichas salinas menciona más de una treintena, la mayor parte de los cuales habían sido explotados hasta el momento por particulares sin contar con autorización regia. Su examen permite comprobar hasta qué punto la regalía de la sal había sido menoscabada en favor de los intereses privados de diversos agentes, entre los cuales figuraban importantes miembros de la nobleza ${ }^{59}$ :

- Aceña mayor

- Aceña nueva

- El pozo que tenía Fernando de Saravia

- $\quad$ El pozo que tenía Gonzalo de Segovia

- Pozos que tenía el conde de Coruña

- Pozos que tenía don Hurtado

- El pozo de "La Coracha"

- $\quad$ El pozo de Rodrigo

- El pozo de Falcón Esteban

- Los pozos que están aparte de Portillo con los de "Alberones" y con la alberca de Fernán Rodríguez

- Las "pertenencias" de Mastano que tenía el Cardenal, que son cinco pozos

- Otra "pertenencia" de Mastano que tenía García Bravo, que son dos pozos

- El pozo nuevo que está aparte de Portillo

- Dos pozos de "los padres"

- La "pertenencia" de Azayuelo que son dos pozos

- La "pertenencia” de Monteviejo que son dos pozos

- Las “pertenencias" de Mari Bivas y Barchilón

- La "pertenencia” de Los Novillos, que son dos pozos

- La "pertenencia" de Morales, que es un pozo

- La "pertenencia” de Navafría, que son 4 pozos

- La "pertenencia" de Ribabermeja, dos pozos

- La "pertenencia" de don Juan de Mendoza, dos pozos sin la aceña nueva

- La "pertenencia" del alcaide de Hita

- Otros pozos del alcaide Campuzano

- La "pertenencia" de Luis de Tovar

Como puede observarse, la terminología empleada permite apreciar cómo ya en el siglo XV continuaba operativa una parcelación de las instalaciones en zonas denominadas "pertenencias" asociadas a los pozos de los cuales se extraía el agua

59. AGS, EMR, leg. 23, ff. 160-161. 
salada del subsuelo. No obstante, parece que algunos equipamientos, como las aceñas o norias utilizadas para elevar el agua desde los pozos -se mencionan dos, la "mayor" y la "nueva"-, eran de uso común ${ }^{60}$.

Por otro lado, la cuenta rendida por Pedro de Robles aporta algunos datos relativos a las obras y trabajos realizados en las salinas, para los cuales fue necesario contratar desde el 8 de mayo de 1477 poceros y aceñeros que cobraron un salario total de $59.725 \mathrm{mrs}$. hasta alçadas eras -el fin de la campaña a fines del verano-, así como peones encargados de "arrodillar" y labrar en las salinas desde el 6 de mayo, de nuevo hasta alçadas de heras, por cuyos jornales se pagaron $142.951 \mathrm{mrs}$. incluyendo el vino que bebieron, la cebada destinada a las acémilas utilizadas para hacer funcionar las aceñas y transportar materiales y sal, y los gastos en el secado de la sal y su trasporte al corral donde se almacenaba. El instrumental comprado para la labra y limpieza de los pozos incluía maromas, rodillos, espuertas, sogas; mástiles, pertigales y varas para sacar agua; pellejos, palas, bramante, hilo, agujas, madera, clavos, escudillas de madera y "medidas" de capacidad para la sal, además de sellos para controlar su "guía" y venta de acuerdo a la legislación. Asimismo, entre las obras de mejora acometidas en La Olmeda se menciona de forma expresa el levantamiento de 114 tapias, la realización de puertas, plegaje y barda para las tapias, y la construcción de un recocedero o estanque destinado a la concentración de la salmuera en los meses previos al verano, desde donde se suministraba a las diferentes piscinas, albercas o eras en las cuales se producía la cristalización de la sal por evaporación del agua. En total, los gastos realizados en 1477 -que incluían otras partidas como la compra de 5 mulos y un rocín, gastos por notificar cartas de los reyes a ciertas villas y lugares tocantes a las mencionadas salinas y otros desembolsos acordados por "iguala"- ascendieron a $260.628 \mathrm{mrs}$., cantidad algo menor a los 295.736 mrs. gastados en $1478^{61}$.

Por su parte, los trabajos realizados en las salinas de Morenglos, localizadas en las inmediaciones de Alcolea de las Peñas y formadas por dos "pedazos" y cuatro pozos - por lo tanto de mucha menor entidad-, ascendieron en 1477 a 15.108 mrs. empleados en el pago de los poceros que trabajaron en la explotación desde el 15 de mayo hasta alçado eras (5.000 mrs.); en la limpieza y labra de las instalaciones (2.040 mrs.); en la compra de mástiles, pertigales y varas para sacar agua; y en "arrodillar" y sacar la sal $(8.068 \mathrm{mrs} \text {. })^{62}$. Por el contrario, en 1478 los gastos en esta salina solo ascendieron a $4.000 \mathrm{mrs}$. destinados al pago de un hombre y un mozo durante 6 meses y medio ${ }^{63}$.

Además de los mencionados pozos y "pertenencias" tomados por el receptor Pedro de Robles se conserva el siguiente listado de salinas y pozos explotados

60. Sobre el funcionamiento y tradición técnica de este tipo de norias ver Ó. CRUZ GARCÍA, "Norias de tradición mudéjar en las salinas de Imón (Guadalajara)", Revista de Folklore, 107 (1989), pp. 147-160.

61. 275.736 mrs. por la limpieza y labra de ciertas tapias y $20.000 \mathrm{mrs}$. por su gasto y el de 4 hombres y un mozo que estuvieron en las salinas de Olmeda 6 meses y medio. AGS, EMR, leg. 23, f. 162 .

62. AGS, EMR, leg. 23, ff. 160-161.

63. AGS, EMR, leg. 23, f. 162. 
en 1477 por diversos particulares y monasterios -algunos de los cuales ya hemos mencionado con anterioridad-, cuyos derechos estaban reconocidos por la Real Hacienda $^{64}$ :

- 4 pozos de los frailes del Parral que eran de Diego de Segovia

- "Pertenencia" con [en blanco] pozos de los frailes de Sacramenia

- Otra "pertenencia" de los frailes de Valbuena

- Salinas de Portillo del duque del Infantado

- Salinas de Imón y Anchuelo del alcaide de Atienza [García Gravo de Lagunas]

- $\quad$ Ciertos pozos que tiene en Imón una dueña viuda

- Ciertas salinas que tiene en Gormellón el maestrescuela de Sigüenza

- Ciertas salinas en Gormellón de [ilegible]

- Salinas que hay en Rienda

- Salinas que hay en Paredes

- $\quad$ Salinas de Romanillos

De esta forma, los arrendamientos de las salinas de Atienza realizados a partir de inicios de la década de 1480 - una vez que la renta salió de nuevo en almoneda- se refieren fundamentalmente a las de La Olmeda y otras de menor entidad situadas en las inmediaciones de Atienza y Sigüenza, aunque a partir de 1489 las salinas de Imón y Anchuelo revirtieron de nuevo en la Corona como consecuencia del fallecimiento del alcaide García Bravo ${ }^{65}$. Por ejemplo, la licitación realizada en 1481 por Pedro de Cogollos para el sexenio 1481-1487 excluía, por un lado, las salinas de Almalla -que en aquel momento eran propiedad del Comendador Mayor de León don Gutierre de Cárdenas ${ }^{66}$-, Traid, Terzaga, Valdeáguila y sus "pertenencias", situadas en las inmediaciones de Molina de Aragón; las salinas de Imón y Anchuelo, propiedad del alcaide de Atienza García Bravo; las de Portillo, del duque del Infantado; y las dos "pertenencias" llamadas de Navafría que tenían los monasterios de Sacramenia y Valbuena ${ }^{67}$. Del destino de los restantes pozos mencionados en la relación de 1477 no tenemos demasiadas noticias, aunque todo apunta a que los derechos de explotación volvieron, en algunos casos, a manos de la Corona. Por ejemplo, según figura en una relación de cuenta de 1481, los cuatro pozos de sal que tenía el Parral de Segovia, valorados en 40.000 mrs., fueron quitados al mencionado monasterio jerónimo a cambio de la entrega de $30.000 \mathrm{mrs}$, siguiendo el mismo mecanismo descrito en el cuaderno de 1447 para la recuperación del pozo que tenía en las salinas de Medinaceli el abad de Huerta, a la postre infructuosa ${ }^{68}$.

A pesar de la restauración de la legalidad operada, la Corona nunca dejó de luchar contra las encubiertas relacionadas con la explotación salinera llevada a cabo

64. AGS, EMR, leg. 23, f. 161.

65. AGS, EMR, leg. 49, ff. 359-360.

66. Así aparecen en AGS, EMR, leg. 29, f. 74. La propiedad de Gutierre de Cárdenas sobre estas salinas ya se menciona en diciembre de 1478. SNAHN, Priego, C. 12, doc. 1-2.

67. AGS, EMR, leg. 30, ff. 250-251; leg 31, f. 279.

68. AGS, EMR, leg. 29, f. 74. 
en la zona, especialmente las vinculadas con la apertura de nuevos pozos ilegales. En algunos casos, se observa la extralimitación de algunos pretendidos propietarios en el cumplimiento de la legislación tributaria. Así, el 26 de junio de 1483 los reyes ordenaban mediante una cédula a Gonzalo Bravo de Lagunas, hermano del alcaide de Atienza García Bravo, presentar ante los contadores mayores los títulos que legitimaban la labra de sal en un pozo que decía ser suyo llamado "La Casa", situado en las salinas de La Olmeda en una heredad propiedad de Íñigo López de Matute, vecino de Madrid, que este a su vez había obtenido en casamiento con su mujer Leonor de la Mota, pues...

...segund las leyes e hordenanças d'estos nuestros reygnos e condiçiones del quaderno de las rentas de las salinas de Atiença ningunas nin algunas personas pueden abrir pozo nin alverca nin otra cosa alguna para fazer sal syn que primeramente nos sea notefycado, e mandemos çerca d'ello lo que a nuestra merçed plugiere ${ }^{69}$.

Gracias a documentos posteriores sabemos que los derechos de Gonzalo Bravo de Lagunas se fundamentaban en cierto contrato suscrito con Íñigo López Matute, en nombre de su mujer Leonor de la Mota, según el cual la explotación de este pozo se le cedía a cambio del pago anual a perpetuidad de 500 fanegas de sal "guiadas" $"$. El caso no es ni mucho menos aislado. De nuevo antes de octubre de 1488 los reyes ordenaban -después de haber sido informados por el contino Gómez de Córdoba de la existencia de ciertos fraudes-, embargar y "vedar" ciertas salinas situadas en el obispado de Sigüenza, medida a la cual se sumaba la prohibición de su labra y de la venta y "guía" de la sal allí producida. Según se deducía de la pesquisa llevada a cabo, algunas salinas se avían ensanchado de como heran antes e abierto de nuevo -algo prohibido según el cuaderno- mientras que en otros casos sus pretendidos propietarios no habían entregado los títulos que legitimaban su posesión ${ }^{71}$. Entre estos últimos se encontraba Luis de la Cerda, duque de Medinaceli, que alegaba no haber podido presentar ante los contadores mayores en el término asignado para ello los títulos originales en los cuales se reconocía su derecho a explotar las salinas situadas en el término de Medinaceli, algunas de las cuales habían sido cedidas posteriormente a otras personas. Por otra parte, entre las salinas embargadas también se encontraba el pozo de "Alandete", cuya explotación había sido traspasada en favor del duque por el monasterio de Huerta, que

69. AGS, EMR, leg. 35, f. 288.

70. AGS, RGS, mayo de 1493, f. 294. El impago por parte de los herederos llevó asociada una solicitud de ejecución por parte de Íñigo López Matute, autorizada por los reyes el 25 de mayo de 1493. No obstante, el pleito coleaba todavía en 1494. El 3 de septiembre de este año los reyes daban una sobrecarta referida al mencionado asunto. AGS, RGS, septiembre de 1494, f. 147.

71. "Sepades que yo soy ynformada que por virtud de una carta qu'el rey mi señor e yo mandamos dar librada de los nuestros contadores mayores se ha puesto çierto enbargo e vedamiento en çiertas salinas que son en el obispado de Sygüença, asy en el fazer de la sal d'ellas como en el vender e guiar d'ella, el qual dicho enbargo se puso diziendo que algunas de las dichas salinas se avían ensanchado de como heran antes e abierto de nuevo e otras porque los que las poseen no mostraron los títulos d'ellas ante Gómez de Córdova, contino de mi casa qu'el rey mi señor e yo enbiamos a fazer pesquisa de las dichas salinas". AGS, EMR, leg. 45, f. 273. 
lo tenía previamente como merced, según ya ha quedado señalado anteriormente. Ante la queja formulada por don Luis de la Cerda, los reyes ordenaban el 28 de octubre de 1488 al alcaide de Atienza Rodrigo de Torres examinar los títulos originales que habilitaban el aprovechamiento de las mencionadas salinas por parte del duque, así como el título original que tenía el monasterio de Huerta para explotar el pozo y el traspasamiento que la institución había realizado en favor del noble. Una vez comprobada su veracidad el alcaide quedaba autorizado para levantar el embargo y la prohibición de venta de la sal labrada en estos pozos, aunque se le encomendaba la realización de una pesquisa antes de 90 días relativa a la forma observada entre 1454 y 1464 en la venta y "guía" de esta sal, en la cual debían comparecer los arrendadores mayores de Atienza así como el duque y las personas a las cuales este había cedido el aprovechamiento de sus salinas ${ }^{72}$. Todavía a comienzos del siglo XVI seguían las pesquisas referidas a los derechos de propiedad de algunas de estas explotaciones. Por ejemplo, gracias a una relación de las cantidades gastadas en 1501 en diversos pleitos por el recaudador mayor de las salinas atencinas Juan de Álamos, sabemos que los reyes habían remitido ciertas cartas a los dueños de determinados pozos situados en el obispado seguntino para que traxesen los títulos que tenía d'ellos al tiempo que ordenaban una probanza relativa a la propiedad del pozo que explotaba el monasterio de Sacramenia ${ }^{73}$.

A pesar de las medidas articuladas, lo cierto es que la explotación de la sal llevada a cabo por particulares siguió siendo una realidad conocida por la Corona, aunque tolerada en algunos casos. Basta con señalar la inclusión entre las fianzas obligadas por Juan de Álamos, vecino de Medina del Campo, para el arrendamiento de las salinas de Atienza entre 1498 y 1503 de los siguientes bienes raíces, entre los cuales se incluían sendos pozos de sal aprovechados por dos importantes miembros de la familia Mendoza:

- Una heredad de "pan llevar" propiedad del Adelantado de Cazorla don Hurtado de Mendoza situada en el lugar de Carabias, cerca de las salinas de Atienza, con el pozo de hacer sal de Malpica, propiedad del Adelantado en el término de dicho lugar. Ambos bienes se obligaban por cuantía de $400.000 \mathrm{mrs}$.

- La heredad de "Alterpeque", en término de Talamanca, y el pozo de sal llamado de la Señora, que era una de las "pertenencias" de las salinas de Anchuelo, así como el molino de Valdesaz, en la ribera de Caspueñas -tierra de Brihuega-, propiedad del Conde de Coruña, y obligado por cuantía de $500.000 \mathrm{mrs}^{74}$.

72. AGS, EMR, leg. 45, f. 273. El 14 de marzo de 1489, los reyes levantaban el embargo sobre el pozo de "Arandete". AGS, RGS, marzo de 1489, f. 291.

73. AGS, EMR, leg. 66, f. 371.

74. AGS, EMR, leg. 64, ff. 483-484. 


\section{El COMERCiO DE LA SAL DE AtienZA}

2.1. Régimen de explotación, áreas de exclusividad y precios de venta

Como es bien sabido, la importancia fiscal de las salinas para la Corona radicaba en la cesión de su explotación directa a compañías de arrendadores que se encargaban en régimen de monopolio de organizar la producción, almacenar la sal y distribuirla y venderla por las áreas de exclusividad asignadas a cada salina a un precio tasado para la primera venta que garantizase un beneficio importante a los arrendadores y, por ende, a la Monarquía la posibilidad de obtener una buena rentabilidad por el alquiler. El sistema se fue configurando paulatinamente a partir del siglo XIII. Ya en época de Fernando III tenemos noticia de los primeros arrendamientos y precios tasados, mientras que el reparto del territorio castellano en áreas de venta exclusiva en las cuales solo se podía consumir la sal procedente de una determinada salina se configuró probablemente entre fines del siglo XIII y comienzos del XIV ${ }^{75}$. Por ejemplo, Fernando IV concedía en 1304, a instancias de su madre y regente María de Molina, licencia a Valladolid para comprar sal no solo en Atienza y Molina, como se había ordenado recientemente en una carta, sino en cualquier otro punto, pues hasta el momento había sido habitual el abastecimiento de la villa a partir de la sal de las Navas e de las salinas de Rusio e de las otras salinas $^{76}$. El privilegio, confirmado por Alfonso XI en 1330 y vigente en el siglo XV como recuerda el cuaderno de $1447^{77}$, parece indicar que la configuración del área de exclusividad de Atienza era un fenómeno reciente en 1304.

Como señala M.Á. Ladero Quesada, el régimen de venta monopolístico establecido estaba íntimamente relacionado con las facultades otorgadas a los arrendadores de las salinas para controlar el sistema de producción y venta y evitar, por un lado, el contrabando asociado a la circulación de la sal de otras procedencias en el área de exclusividad de Atienza, y por otro, la venta de sal de otras salinas o territorios a un precio menor al tasado. Ello se hacía a partir de la emisión de albaranes o recibos entregados como justificante a los agentes que habían comprado sal de forma legítima, y también mediante la inspección de los lugares de almacenamiento. No obstante, la actividad de los agentes encargados del control o albaleros, fuente de diversas quejas y demandas, siempre se mantuvo bajo sospecha en virtud de los abusos llevados a cabo al amparo de su posición privilegiada. Por ejemplo, en las Cortes de 1322 los procuradores señalaron cómo muchos aluareros encargados de escodriñar la circulación de la sal de Atienza en su área de exclusividad decían que la hallada en las casas de los labradores de muchas aldeas, realmente comprada en el mercado público para su consumo propio o el de sus ganados, non es daquella sal que deue andar en aquella tierra e en aquella comarca, lo cual llegaban a justificar introduciendo en los lugares investigados sal de otra

75. M.Á. LADERO QUESADA. Fiscalidad y poder real..., pp. 89-91.

76. A. BENAVIDES. Memorias de D. Fernando IV de Castilla, Madrid, Imprenta de José Rodríguez, 1860, vol. II, doc. CCLXXIV, p. 409.

77. CSA, ley 2, p. 416. 
procedencia. Por ello se prohibió a los albaleros realizar inspecciones en las casas y aldeas, autorizando únicamente su control sobre los "salineros" en los puertos y logares por donde sienpre se guardó. Asimismo se ordenaba a los oficiales concejiles confiscar toda la sal vedada que los propios albaleros vendían en las villas y mercados de forma fraudulenta, escudándose en su condición de inspectores ${ }^{78}$. Otros documentos se refieren al cumplimiento de esta disposición de Cortes: por ejemplo, Alfonso XI prohibió en algún momento de su reinado el embargo de sal en las casas de los beneficiados de la iglesia de Sigüenza ${ }^{79}$.

En este sentido, el ordenamiento dado por Alfonso XI en abril de 1338 para regular el mercado de la sal se considera un texto fundamental por cuanto más allá de reafirmar el monopolio de la Corona sobre todas las salinas del Reino, embargadas a sus propietarios, introducía nuevos elementos que facilitaron el posterior establecimiento de novedades fiscales que, de haber triunfado, hubieran convertido probablemente la venta de la sal en una de las principales rentas de la Monarquía. Así, el rey declaraba la libertad de circulación de la sal por el territorio - a excepción de Andalucía y Murcia- a un precio de venta fijado en 6 mrs. por fanega en el interior y 4,5 mrs. en los puertos costeros, mientras que se ordenaba a aquellos antiguos propietarios de salinas que tuvieran derecho a continuar con su explotación, o fuesen beneficiarios de parte de la producción como compensación por la renuncia de sus derechos en favor de la Corona, vender la sal únicamente a los arrendadores reales a precio muy inferior al de la tasa ( 1 o 2 mrs. por fanega $)^{80}$.

No obstante, la mayor innovación llegó entre 1338 y 1345 cuando el monarca ordenó establecer un sistema de cupos a partir del reparto a cada ciudad, villa o lugar de cantidades en sal que obligatoriamente debían comprar al precio tasado. Era la contrapartida lógica a la libertad de circulación de la sal por el territorio reconocida en 1338 y a la supresión del sistema de control de venta y almacenaje que tantas quejas había provocado, aunque la oposición de las ciudades, expresada en las Cortes de 1351, terminó socavando la aplicación de una innovación que a la larga hubiera llevado al establecimiento de una contribución directa muy cuantiosa sufragada por los vecinos pecheros de las ciudades similar a la gabelle $d u$ sel recaudada en Francia ${ }^{81}$. El fracaso del régimen de cupos de sal según repartimiento introducido por Alfonso XI, mencionado por última vez en las Cortes de 1379 en las cuales Juan I se comprometió a terminar con el sistema una vez concluido

78. Cortes de los antiguos reinos de León y Castilla, Madrid, Real Academia de la Historia, 1861, vol. I, Pet. 47, pp. 349-350.

79. T. MINGUELLA Y ARNEDO. Historia..., vol. 2, suplemento a la Colección Diplomática, núm. 219, p. 680. Traslado de la provisión de Alfonso XI realizado en 1519.

80. E. GONZÁLEZ CRESPO. Colección..., doc. 257, pp. 434-439. Análisis del texto en S. LÓPEZ CASTILLO, "El ordenamiento jurídico del comercio de la sal y Salinas de Añana (Álava)", Anuario de Estudios Medievales, 14 (1984), pp. 449-453.

81. M.Á. LADERO QUESADA. Fiscalidad y poder real..., pp. 92-95. Sobre la gabelle du sel francesa B. CHEVALIER, “Aux origines de la Ferme. Les villes et le monopole d'approvisionnement des greniers à sel (fin XIVe-milieu XVIe siècle)", en J.-C. HOCQUET. (ed.) Le roi, le marchand et le sel, Lille, Presses Universitaires de Lille, 1987, pp. 133-150. 
el plazo de arrendamiento vigente ${ }^{82}$, facilitó el retorno a la situación anterior, es decir, la venta libre de la sal a precio tasado en áreas delimitadas para cada salina según su producción. Ello permitía asegurar las ventas y garantizar unos precios de arrendamiento estables, al tiempo que suponía la reintroducción de los tradicionales sistemas de inspección del almacenaje y distribución del producto. Sin embargo, en las zonas por las cuales circulaba la sal de algunas salinas explotadas por particulares -como las de Medinaceli o las de Almalla- perduró el sistema de asignación de cupos fijos comprados obligatoriamente a un precio tasado. Por ejemplo, en 1432 las cuadrillas y lugares de Medinaceli, Barahona y Luzón estaban obligadas a consumir 5.000 fanegas de sal procedentes de las salinas del conde de Medinaceli a un precio tasado en 16,66 mrs./fanega ${ }^{83}$, mientras que el 20 de diciembre de 1478 el concejo de Cañaveras, villa de señorío de Pedro Carrillo de Mendoza, II conde de Priego, se obligaba a tomar anualmente 70 fanegas de sal de la medida mayor de las salinas de Almalla, Terzaga y Traid, que en aquel momento eran propiedad del Comendador Mayor de León don Gutierre de Cárdenas, así como toda e qualquier sal que ovieren menester e pudieren comer e gastar, a los precios en los cuales el "común" de Molina las tomara, lo cual parece indicar que la sal de estas salinas también circulaba por este territorio ${ }^{84}$.

Esta es, por lo tanto, la situación imperante en el siglo XV en las salinas de titularidad regia no enajenadas, bien conocida gracias al tantas veces mencionado cuaderno de 1447. En él se establece, en primer lugar, el amplísimo término por el cual podía circular la sal atencina, que abarcaba desde el río Arlanza hasta el Tajo y desde la frontera portuguesa hasta la frontera con Aragón, lo cual se encontraba en consonancia con los elevados niveles de producción de este conjunto de explotaciones. No obstante, existían algunas salvedades en la delimitación general que conviene tener presentes. Por ejemplo, desde Madrid hacia el sur solo se podía consumir la sal de las salinas de Espartinas, en el actual término de Ciempozuelos, que también circulaba de forma exclusiva en Plasencia y al sur del río Alberche, siendo la villa de Escalona el último punto de consumo de la sal de Atienza por esta parte. Por lo tanto, la línea divisoria entre las áreas de Atienza y Espartinas se encontraba delimitada por la localidad de Zorita y el término de Guadalajara, donde se establecía el consumo exclusivo de la sal de Atienza. Sin embargo, en Madrid se podría consumir indistintamente sal de Espartinas y Atienza. Al norte de la línea acotada por el Alberche, Talavera y Oropesa circulaba la sal de Atienza, que no entraba, sin embargo, en el término de Plasencia ni en el de Trujillo, de forma que la divisoria al oeste de Talavera se desplazaba del Tajo hacia el Sistema Central. Por su parte, en la parte norte la frontera estaba marcada por los ríos Duero, Pisuerga y Arlanzón, mientras que hacia el este el cuaderno de 1447 mencionaba como límites, en la zona fronteriza con Aragón, a Ágreda, Cervera, San Pedro de Yanguas y Soria con su tierra, prohibiéndose la entrada de sal de Atienza en la tierra de Cameros. En toda esta inmensa región solo Valladolid tenía autorización

82. Cortes..., vol. II, p. 299. M.Á. LADERO QUESADA, “La Hacienda Real...”, p. 442.

83. M.Á. LADERO QUESADA. "La renta de la sal...”, vol. I, p. 829.

84. SNAHN, Priego, C. 12, doc. 1-2. 
para consumir sal de otras procedencias -Añana, Rosio...-, según se establecía en el ya mencionado privilegio dado en $1304^{85}$.

Por otra parte, según privilegio otorgado por Enrique II y confirmado por Juan I en agosto de 1379, toda persona del Reino estaba autorizada a llevar sal de las salinas que el conde de Medinaceli tenía en esta villa para su venta en cualquier territorio, a excepción de Soria, Almazán, Atienza ni las otras villas e lugares que fueren de Mosse Beltrán [Duguesclin], aunque la sal podría circular libremente por estas áreas siempre y cuando no se llevase a cabo en ellas ninguna venta ${ }^{86}$. No obstante, poco después este privilegiado régimen de venta cambió, quizás como consecuencia de la necesidad de moderar el menoscabo que suponía la circulación de la sal de Medinaceli para los arrendadores que tomaban a su cargo las salinas del rey. Al parecer los arrendadores de las salinas del obispado de Sigüenza llegaron a un acuerdo con la condesa Isabel de la Cerda - cuyo cumplimiento ordenaba Juan I en abril de 1386- según el cual le fezieron dexamiento de sus salinas de Medinaceli a cambio de delimitar un área de venta exclusiva para la sal allí producida, que solo podría entrar y venderse en las ciudades de Osma y Soria, en las villas y términos de Almazán, Berlanga, Morón, Monteagudo, Deza, Serón [de Nágima] y Gomara, así como en todas las villas y lugares de allende el rio Duero donde entraba y se vendía hasta el momento la sal de las salinas del obispado de Sigüenza, aunque San Esteban de Gormaz y su término quedaban al margen de la región delimitada $^{87}$. Desconocemos, empero, si el régimen de venta concertado en 1386 tuvo continuidad en el futuro ya que, tanto Enrique III en abril de 1391 y de nuevo en diciembre de 1393, como Juan II en febrero de 1411, confirmaban el privilegio de venta libre de la sal de Medinaceli, con las salvedades mencionadas ${ }^{88}$, mientras que el cuaderno de arrendamiento de las salinas de Atienza de 1447 no incluye mención alguna al área delimitada. Sin embargo, los titulares de la casa condal trataron en el futuro de hacer valer sus derechos en este sentido. Así, según denunciaba en 1479 el conde de Medinaceli don Luis de la Cerda, los receptores de las salinas de Atienza en 1478 y 1479 -a la sazón el alcaide de Atienza García Bravo y Pedro de Robles- habían quebrantado la licencia regia que tanto él como sus antecesores tenían para vender la sal de sus salinas de Medinaceli y Saelices por la ciudad de Soria y su tierra e por otras villas e logares de sus comarcas libre e esentamente syn le ser enpedido nin cotrallado por persona nin personas algunas ${ }^{89}$.

Finalmente, según el privilegio dado en agosto de 1504 por el cual los reyes donaban al comendador de Villarrubia mosén Diego de Aguilera un pozo en

85. La delimitación aparece señalada en CSA, leyes 2 y 5, pp. 415-416 y 418.

86. M.L. PARDO RODRÍGUEZ. Documentación..., doc. 60, pp. 60-61. Asimismo teóricamente, según privilegio real dado por Alfonso X en abril de 1253, la sal de Saelices, Medinaceli y Molina tampoco podría entrar en la ciudad de Cuenca para evitar perjuicios al cabildo catedralicio conquense que tenía como merced algunas salinas (Valtablado, Tragacete y otras). J.M. SÁNCHEZ BENITO. Las tierras de Cuenca y Huete en el siglo XV. Historia económica, Cuenca, Servicio de Publicaciones de la Universidad de Castilla-La Mancha, 1994, p. 180.

87. M.L. PARDO RODRÍGUEZ. Documentación..., doc. 94, pp. 243-244.

88. Ibid., docs. 98, 100, 108 y 139, pp. 246-247, 250-251, 261-262 y 317-318.

89. AGS, RGS, septiembre de 1479, f. 127. 
Terzaga junto al terreno necesario para construir eras y "recocederos", la sal allí producida solo podía ser vendida en la villa de Molina y su tierra donde agora non se come ni gasta ni acostunbra comer nin gastar la sal de las nuestras salinas de Atiença nin de otras qualesquier nuestras salinas, mientras que también se autorizaba su "guía" hacia el reino de Aragón", lo cual certifica la configuración de una zona de circulación exclusiva para la sal molinesa, que también se exportaba hacia el vecino reino aragonés. En este sentido, lo reducido del término delimitado para la sal de Terzaga, que tampoco aparece reflejado en el cuaderno de arrendamiento de las salinas de Atienza de 1447, parece apuntar hacia unos bajos niveles de producción.

Junto a la prohibición de comercializar otra sal que no fuese la de Atienza en el área de exclusividad delimitada, el cuaderno de 1447 también vetaba la posibilidad de establecer en este espacio alfolíes o almacenes de sal, salvo en Ayllón, Torrelaguna, "Junquera” (¿Yunquera de Henares?), San Esteban de Gormaz y Soria, que eran los únicos puntos de abastecimiento autorizados a los cuales podían acudir los recueros a cargar el producto ${ }^{91}$. Entre estas localidades y las salinas se prohibía almacenar sal por encima de las 4,5 fanegas de la medida de las dichas salinas o establecer cualquier otro alfolí, especialmente en Saelices o en Molina. Por el contrario, más allá del límite de los alfolíes oficiales estaba permitido almacenar el producto sin restricciones, aunque no establecer otros almacenes para cargar ni descargar ni vender sal. Como se puede suponer, el cumplimiento de esta normativa era sumamente complejo, habida cuenta de la amplitud del territorio y de la ausencia de mecanismos de control más allá de los ya existentes a comienzos del siglo XIV. En este sentido, según el cuaderno de 1447 los arrendadores seguían controlando el fraude y el contrabando a partir del sistema de "guía" de la sal mediante la entrega a los compradores mayoristas de un justificante de compra que podría ser solicitado por los albaleros nombrados que, en caso de fraude, debían proceder al embargo de la sal por "descaminada". De igual forma, estos agentes también estaban autorizados para "catar" o inspeccionar las casas donde sospechaban que podían existir alfolíes o almacenes ilegales, siempre y cuando fuesen acompañados de dos "hombres buenos" dados por los alcaldes y oficiales de los concejos donde realizaban la inspección, medida que trataba de frenar abusos ${ }^{92}$. En efecto, las normas de control incluidas en la legislación tributaria se aplicaron en los términos establecidos, tal y como se deduce de algunos testimonios referidos a la casuística concreta. Por ejemplo, don Ça Caro, arrendador de las salinas atencinas en 1490, hizo "descaminar" nueve acémilas cargadas de sal que non

90. AGS, PR, leg leg. 59, doc. 94. La merced quedó registrada en los libros de cédulas de la cámara. AGS, CCA, Ced. 9, f. 118, doc. 1.

91. El régimen de alfolíes seguía operativo a fines del siglo XV tal y como parece apuntar la obligación de 10.000 fanegas de sal que estaban en poder de los alcaldes de Ayllón como fianza para el arrendamiento de las salinas de Atienza del período 1498-1503 formalizado por Juan de Álamos, vecino de Medina del Campo. AGS, EMR, leg. 64, ff. 483-484.

92. CSA, leyes 3 y 4 . 
yvan con su guía de sus fazedores, demandadas posteriormente por fray Juan de Buendía, procurador del monasterio de San Bartolomé de Lupiana ${ }^{93}$.

Asimismo, la explotación de las salinas en régimen de monopolio también incluía otras obligaciones. En primer lugar, los arrendadores mayores, además del pago de los situados o gastos fijos que gravaban la renta -entre ellos 50 cahíces de sal (600 fanegas) anuales para el rey ${ }^{94}$ - y de las libranzas u órdenes de pago en los plazos marcados, debían sufragar a su costa la construcción entre el 1 de marzo y el 31 de julio de cada año de 200 tapias de cal y canto de tres varas castellanas de medio paño de largo, una vara y media de alto y dos varas menos quarta de ancho, aunque el rey correría con los gastos de las obras de cimentación donde se han de armar las dichas tapias ${ }^{95}$. En segundo lugar, según las condiciones de arrendamiento establecidas en 1447, los arrendadores estaban obligados a dejar durante el tiempo que durase su contrato una cantidad entre las 40.000 y las 100.000 fanegas de sal para el monarca, que este les pagaría a $3 \mathrm{mrs}$./fanega, aunque la cantidad que sobrepasase las 100.000 fanegas sería tomada sin abonar precio alguno. Posteriormente, los siguientes licitadores estarían obligados a tomar 40.000 fanegas a 7,5 mrs./fanega, lo cual suponía un pago extra de $300.000 \mathrm{mrs}$. más allá de la cantidad concertada en el arrendamiento ${ }^{96}$. Según Ladero la medida obedecía no solo al deseo de beneficio de la Corona sino a la necesidad de asegurar unas cantidades mínimas almacenadas ${ }^{97}$. En este sentido hay que recordar que la producción solía verse resentida hasta que cada nuevo equipo de gestores ponía en marcha la explotación salinera, de manera que la medida articulada era una buena forma de garantizar el abastecimiento durante este período. Finalmente, los arrendadores mayores tenían autorización para disfrutar de unas casas que dizen de Bonilla situadas en las inmediaciones de las salinas de La Olmeda que contaban con ciertas tierras y una huerta, integradas en el patrimonio regio en virtud de ciertas deudas dejadas por un tal Juan Núñez de Guadalajara, ya finado. A cambio debían comprometerse a mantener las casas en buen estado y tejarlas, además de plantar cada año 50 pies de árboles ${ }^{98}$.

En cuanto al precio oficial de venta de la sal, evolucionó al calor de la devaluación monetaria característica del período bajomedieval. En 1369 Enrique II lo fijaba en $10 \mathrm{mrs}$./fanega con carácter general para todo el Reino asi como el Rey don Alfonso nuestro padre, que Dios perdone, ordenó ${ }^{99}$. Por su parte, el cuaderno

93. AGS, RGS, diciembre de 1491, f. 98.

94. Así figura en el arrendamiento de 1447-1452. AGS, EMR, leg. 2, ff. 394v-395r.

95. La obligación ya figura en las condiciones de arrendamiento de 1441-1446. AGS, EMR, leg. 2, f. 350r. Se repite de nuevo en el cuaderno de arrendamiento de 1447. CSA, ley 23, p. 423. No obstante, en el arrendamiento de los años 1447-1452 se distribuyeron las 1.200 tapias correspondientes a todo el período de la siguiente forma: en 1448 se harían 300 tapias, en 1449 y 1450250 tapias anuales, y en 1451-1452 otras 200 tapias anuales. AGS, EMR, leg. 2, ff. 394v-395r.

96. CSA, leyes 16 y 25, pp. 421-422 y 424. Ver también AGS, EMR, leg. 2, ff. 394v-395r.

97. M.Á. LADERO QUESADA. “La Hacienda Real...”, pp. 171-172.

98. CSA, ley 37, pp. 427-428.

99. Cortes..., vol. II, ley 60, p. 180. 
de 1447 establecía un precio de venta para la sal atencina de $16 \mathrm{mrs}$./fanega ${ }^{100}$ (2 reales al cambio oficial) -de los cuales se pagaría un maravedí en concepto de alcabala - mientras que en 1477 había ascendido a $60 \mathrm{mrs}$./fanega para compensar la devaluación de la moneda de cuenta, aunque en 1478, según figura en un documento, los situados en sal se pagaron a $80 \mathrm{mrs}$./fanega. Finalmente, a partir del arrendamiento de 1481 el precio quedó fijado de nuevo en los $60 \mathrm{mrs}$./fanega iniciales $^{101}$.

Por otro lado, ya hemos señalado cómo la sal producida por los particulares que explotaban salinas y pozos al margen de los incluidos en el arrendamiento de las salinas de Atienza solo podía venderse a los arrendadores mayores a $3 \mathrm{mrs}$./fanega, según reconocía en el cuaderno de $1447^{102}$, aunque la orden no siempre se cumplió en estos términos. Por ejemplo, Diego Hurtado de Mendoza, II marqués de Santillana, recibía en junio de 1468 licencia de Enrique IV para vender la sal de su pozo de Portillo así como las 600 fanegas anuales que tenía situadas en las salinas atencinas a cualesquier concejos, personas o recueros que las comprasen en los tiempos y precios que quisiese sin caer en pena o caloña alguna, medida muy favorable al noble argumentada en la necesidad de paliar los efectos negativos que la situación conflictiva vivida en Castilla desde 1465 había tenido en el mercado salinero $^{103}$.

\subsection{La fallida restauración del sistema de "cupos" de venta a fines del siglo XV}

Probablemente, tanto las dificultades para controlar el fraude y el contrabando como el menoscabo provocado en la renta por las explotaciones particulares, llevaron a comienzos de la década de 1480 a un intento de restauración del régimen de venta establecido por Alfonso XI a partir de la asignación de cupos fijos de sal a cada ciudad, villa y lugar según repartimiento, circunstancia ignorada hasta el momento que pudo haber condicionado la evolución posterior de la renta. No obstante, las resistencias mostradas por las ciudades y villas del Reino hicieron finalmente desistir a la Corona de un empeño que respondía fundamentalmente al interés de los recaudadores en obtener unos beneficios seguros a un coste de gestión mucho menor, pues mediante este sistema se podría prescindir de todo el costoso aparato de agentes fiscalizadores.

Ya en la postura presentada en Valladolid el 22 de mayo de 1481 por Juan de la Rúa, vecino de Salamanca, para el arrendamiento de las salinas atencinas desde San Juan de 1481 a San Juan de 1487 se incluía una condición referida al reparto

100. CSA, ley 17, p. 422.

101. AGS, EMR, leg. 23, ff. 160-161. No obstante, según el asiento de la receptoría de las salinas de Atienza dada al Luis de Alcalá en 1478 el precio de pago de los "situados" en sal quedó establecido en 80 mrs./fanega. AGS, EMR, leg. 25, f. 149. En 1481, según una relación de cuenta -probablemente previa al arrendamiento realizado aquel año- el precio de cada fanega situada quedó establecido en $90 \mathrm{mrs}$./fanega. AGS, EMR, leg. 29, f. 74. No obstante, en las condiciones de licitación formalizadas aquel año se estableció el precio de 60 mrs./fanega. AGS, EMR, leg. 30, ff. 250-251.

102. CSA, ley 6, pp. 418-419.

103. SNAHN, Osuna, C. 1854 , doc. 1. 
de 15.000 fanegas de sal a las ciudades, villas y lugares incluidas en los límites de las salinas para que cada ciudad tomase la cantidad repartida en sal y la pagase a $60 \mathrm{mrs}$./fanega ${ }^{104}$. Aunque la titularidad del arrendamiento finalmente recayó en Pedro de Cogollos, vecino de Alcalá, tras la presentación de nuevas pujas, esta condición inicial fue mantenida.

Las ciudades y villas incluidas en los límites de las salinas reaccionaron ante lo que consideraban no era sino una ynpusiçión nueva enviando procuradores ante la reina para suplicar que les mandase quitar el dicho repartimiento. Tras remitir el asunto al examen del Consejo Real y de los contadores mayores, Isabel I aceptaba en una cédula, a la vista de las deliberaciones de ambos órganos, qu'el dicho repartimiento no pasase declarando nulo el arrendamiento realizado por Pedro de Cogollos, pues la dicha condiçión con él asentada non se puede conplir por ser agraviada contra los pueblos, y ordenando al mencionado arrendador pagar todos los mrs. de su cargo en 1481 en sal al precio de 60 mrs./fanega. Quizás la presión fiscal ya era lo suficientemente importante, especialmente tras el establecimiento de la contribución de la Hermandad sustitutiva de los servicios de Cortes, como para establecer una nueva carga cuyo planteamiento, en realidad, solo favorecía en aquel momento al recaudador mayor.

Una vez conocida la decisión adoptada, Pedro de Cogollos elevaba un memorial de agravios a la reina en el que denunciaba el daño recibido. De nuevo su resolución se encomendó al Consejo Real y a fray Hernando de Talavera, prior de Prado y experto hacendista, que se encargaron de analizar punto por punto las condiciones solicitadas por el financiero para hacerse cargo de la recaudación de la renta, incluidas en un escrito de capitulaçión remitido al Consejo. Estas condiciones con la respuesta al margen dada por Talavera y ciertos miembros del Consejo, fueron las siguientes:

- Descuento de 30.000 mrs. entregados en concepto de salario a García González de Sevilla y al alcalde Proaño por poner enbargo en la sal y fazienda de mi hermano Yñigo López, y descuento de los pagos ya librados. En este sentido, el Consejo aceptaba el cobro de 10.000 mrs. por parte de García González y otros 10.000 mrs. por parte del alcalde Proaño, mientras que ordenaba la devolución de los $10.000 \mathrm{mrs}$. restantes al arrendador. Por otra parte se consideraba justo recibir en cuenta a Pedro de Cogollos la cantidad que se averiguase había pagado ya en concepto de libranza.

- Descargo de las pujas y "medias pujas" realizadas en el cuerpo de la renta y de los "prometidos" y "cuartas partes de puja" que debían percibir las personas que los ganaron, argumentado en el incumplimiento de las condiciones aceptadas por los contadores para formalizar el arrendamiento. En este punto el Consejo Real respondió de forma desfavorable al arrendador: las cantidades correspondientes a las pujas realizadas conforme a derecho serían cargadas en el precio de la renta, y Pedro de Cogollos de-

104. AGS, EMR, leg. 30, ff. 250-251. 
bería abonar en sal las cantidades ganadas en concepto de "prometido" o "cuartas partes de puja" a sus legítimos beneficiarios.

- Solicitud de cierto descuento en los pagos en sal acordados. Según declaraba el arrendador se había producido un menoscabo en la sal cifrado en más de un $25 \%$ motivado por aver pasado el ynvierno de las aguas -es decir la época de lluvias, necesarias para el correcto funcionamiento de las salinas-y por los hurtos y malos recabdos que en la azienda a avido. Ello hacía inviable la satisfacción de las obligaciones contraídas sin comprometer más de $600.000 \mathrm{mrs}$. de la hacienda del arrendador, según señalaba. Tras obtener información de los menoscabos realizados en las salinas, efectivamente cifrados en un porcentaje cercano al $25 \%$ de su capacidad productiva, el Consejo Real terminó aceptando un descuento del $10 \%$ en el pago de los situados y de las cantidades que debía recibir la Corona una vez abonado el gasto fijo.

- Renuncia de la Real Hacienda a percibir derechos por la expedición de la carta de recudimiento y otros derechos porque basta lo gastado y perdido syn esperar de otros años ganar. El Consejo Real aceptó, en este caso, el pago de la mitad de los derechos de recudimiento de 1481 .

- Descuento de 20.000 mrs. perdidos por el recaudador en la "guía" de la sal llevada por el escribano de Hernando de Zafra y por la sal comprada y "guiada" por el alcaide de Atienza. En este caso el Consejo Real aceptó únicamente el descuento de la cantidad que se averiguase había "guiado" el mencionado escribano.

- Ampliación de los plazos de pago en caso de faltar alguna sal para cumplir el total del cargo, con objeto de poder comprarla y evitar así cualquier agravio. Asimismo, en caso de que sobrase alguna sal, Pedro de Cogollos solicitaba facultad para venderla en las salinas o fuera de ellas dentro del plazo delimitado por el Consejo para sacarla y "guiarla". De nuevo el órgano consultivo aceptó estas demandas: el plazo de pago de las cantidades de sal comprometidas se amplió hasta finales de agosto de 1482 -el plazo inicial de arrendamiento se consumía en San Juan-, fecha límite para vender y "guiar" la sal sobrante tanto que sin fraude alguno pague todo lo que ha de pagar.

- Descuento de 30.000 mrs. por los gastos de los tres receptores y tres escribanos que acudieron con el arrendador para requerir a los concejos que fuesen por repartimiento, es decir, que aceptasen las nuevas condiciones que implicaban la asignación de cupos de sal cuya compra sería obligatoria. El Consejo solo aceptó en este caso un descuento de 10.000 mrs.

- Descuento por ciertas cantidades de sal sacadas de las salinas previa autorización. Entre ellas 1.000 fanegas "guiadas" por Juan de Torres y otras 2.000 por la duquesa del Infantado. En este punto el Consejo daba la razón a Pedro de Cogollos señalando cómo paresçe que en esto reçibió este algund agravio pero que aya paçiençia en el descuento. 
- Descuento por los dos meses y tres días que el anterior receptor, Juan de la Rúa, había estado de más en las salinas. En este sentido, aunque el arrendamiento comenzaba en San Juan (24 de junio) Pedro de Cogollos solo pudo comenzar, según indicaba, la explotación desde el 3 de agosto de 1481. Tras la negativa de Juan de la Rúa a dar cuenta de lo recaudado entre ambas fechas, Pedro de Cogollos solicitó el prendimiento del primero en Salamanca, donde estaba avecindado, aunque los contadores posteriormente ordenaron soltarle. El Consejo Real acordó poner el asunto en manos de los contadores.

- Devolución de la hacienda ejecutada por orden del alcalde Proaño a Íñigo López, hermano de Pedro de Cogollos, rematada en 25.000 mrs. a pesar de valer $150.000 \mathrm{mrs}$. El Consejo aceptó su devolución, ordenada mediante provisión, siempre y cuando se reintegrasen a los compradores los 25.000 mrs. pagados.

Como puede observarse las condiciones aprobadas por el Consejo eran claramente favorables a los intereses de Pedro de Cogollos, aunque en algunos casos introducían matices. Por otra parte, al ser un asunto relacionado con la Real Hacienda, los contadores mayores también se encargaron de emitir su parecer que, este caso, fue desfavorable a las decisiones adoptadas por el Consejo Real en virtud del agravio que suponían para la Hacienda. Sin embargo, pese a su oposición, la reina daba el 22 de junio de 1482 desde Córdoba una cédula en la cual legitimaba lo aprobado y declarado por el Consejo e instaba a Pedro de Cogollos a dar nuevas fianzas. No obstante, a pesar del reconocimiento de la mayor parte de sus demandas, el arrendador mostró de nuevo su disconformidad ante la solicitud de fianzas, pues -como señalaba- esta condición no se encontraba en el asiento suscrito con la reina amén de que en el dicho primero año a avido mucha mengua de sal así por ser el primero año como por que plugo a nuestro Señor de dar poca sal en las dichas salinas. Ante la nueva reclamación planteada, la reina volvió a comisionar al Consejo y a fray Hernando de Talavera para la resolución del caso, en cuyo transcurso Pedro de Cogollos presentó un nuevo memorial de agravios en el que se incluían, entre otros, los siguientes puntos:

- Descuento por la falta de adecuación de las medidas de fanegas utilizadas. Aunque el arrendador debía dar toda la sal con la "medida" menor, reconocida inicialmente para la realización del repartimiento, finalmente la sal se tomó con la medida real qu'es el terçio mayor, de lo qual reçibe agravio del terçio de toda la sal segund los señores contadores saben y todos.

- Negativa de los contadores a dar provisiones para que el alcalde Proaño y García González pagasen los 10.000 mrs. que se les ordenó restituir de sus salarios.

- $\quad$ Examen de las pujas realizadas conforme a derecho.

- Descuento completo del diezmo de la sal, según quedó establecido en el asiento suscrito con la reina. La denuncia estaba motivada en la negativa de los contadores a aceptar la quita en las cantidades correspondientes al situado, a pesar de lo señalado en la capitulación firmada. 
- Reconocimiento de la autorización dada para que el recaudador abonase únicamente la mitad de los derechos de recudimiento.

- Descuento de 7.000 mrs. por los gastos de desplazamiento a Vitoria, donde se encontraba el Consejo, además de otros 25.000 mrs. correspondientes a las costas relativas a la ejecución de la hacienda de su hermano Íñigo López.

- Desagravio por ciertas ejecuciones realizadas en el recaudador, relacionadas con el pago de ciertos mrs. de doña Mencía de Lemos, y con la satisfacción en dinero de otros situados y libranzas, a pesar de que según cédula de la reina todos los pagos debían realizarse en sal con la "medida real" y no en dineros.

- Invalidación de todas las mercedes y sobrecartas dadas contra Pedro de Cogollos.

- Denuncia de la ejecución realizada por el alcaide de Atienza por 20.000 mrs. librados al doctor Alonso Manuel, por los cuales le tomaron 1.500 fanegas de sal "de recibo" y 3.000 mrs. de costas.

- Denuncia de la toma por fuerça de 333 fanegas de sal de reçibo llevada a cabo por el conde de Cifuentes diziendo que avrá de aver veynte mill mrs. situados de por vida en las dichas salinas que se catarán los libros. En caso de comprobarse la veracidad de este derecho solicitaba el descuento de esta sal por la dicha medida del repartimiento ${ }^{105}$.

Tras el examen del nuevo memorial de agravios, el cargo anual definitivo quedó establecido en las 31.045 fanegas iniciales por las cuales se había arrendado la renta, aunque se aceptaron finalmente los siguientes descuentos, una vez pagadas 19.410 fanegas en concepto de situado, salvado y libranza:

\begin{tabular}{|l|r|}
\hline \multicolumn{1}{|c|}{ Suspensiones } & Fanegas \\
\hline $\begin{array}{l}\text { Tercio de lo que montan las 19.410 fanegas de la data porque todo fue } \\
\text { medido con la medida real "del recibo", y él no era obligado a pagar salvo } \\
\text { con la medida del repartimiento, que es un tercio menos }\end{array}$ & 6.470 \\
\hline Diezmo de las 19.410 fanegas & 1.941 \\
\hline $\begin{array}{l}\text { Descuento de 10.000 mrs. por lo que gastó en requerir a los concejos que } \\
\text { viniesen a por la sal del repartimiento }\end{array}$ & 166 \\
\hline 20.000 mrs. por lo que guió y llevó el escribano & 333 \\
\hline TOTAL SUSPENSIÓN & $\mathbf{8 . 9 1 0}$ \\
\hline
\end{tabular}

A partir de este momento, el régimen de gestión de las salinas de Atienza volvió a la situación que existía antes del intento de reintroducción del sistema de asignación de cupos llevado a cabo en 1481, aunque encontramos algunas noticias contradictorias que remiten a esta práctica en una escala local y bajo circunstan-

105. Todas las resoluciones del Consejo Real y los memoriales de agravios en AGS, EMR, leg. 31 , f. 280 . 
cias poco explícitas. Por ejemplo, en noviembre de 1489 los reyes ordenaban ver la demanda planteada por Juan Martínez Revuelto, vecino de Guadalajara y procurador del "común" de esta ciudad, referida a la sentencia dada por el difunto doctor de Zamora en el pleito que habían sostenido cuatro o cinco años atrás contra Yuçaf de Vidas, vecino de Atienza, sobre çierta sal que fue repartida al común de la dicha çibdad e su tierra, en la cual se les condenaba a tomar 1.500 fanegas de sal y pagarlas a cierto precio cuyo total fue ejecutado en 100 pares de bueyes ${ }^{106}$. Lamentablemente desconocemos el momento en el cual se llevó a cabo este reparto que, no obstante, supone considerar la aplicación efectiva del sistema de repartimiento de cupos fijos, quizás de forma limitada y como parte de las relaciones entabladas directamente por las autoridades urbanas con los arrendadores y otros agentes autorizados para vender sal, conocidas en otros casos, aunque sin mención a la toma de cupos fijos ${ }^{107}$. Así, el 13 de febrero de 1495 el concejo de Madrid acordaba con Juan de Álamos, recaudador de las salinas de Atienza, el abastecimiento de sal en la villa y tierra a los siguientes precios: $10 \mathrm{mrs}$. el celemín de sal colorada de Imón y 9,5 mrs. el de sal blanca de Atienza ${ }^{108}$. Más adelante, el 20 de septiembre de 1499 el mismo concejo comisionaba a Pedro de Vega para ir a Atienza a tomar asiento con el recaudador de las salinas en relación al precio y forma en que habría de dar la sal dicho año ${ }^{109}$.

2.3. Medidas de control del contrabando y de compensación a los arrendadores

Junto a este intento fallido por reintroducir el antiguo sistema de cupos, la novedad más significativa de las décadas de 1480 y 1490 en relación al arrendamiento de las salinas de Atienza quizás fuese la aparición, cada vez más habitual, de cláusulas en los contratos de arrendamiento destinadas a compensar a los arrendadores por las pérdidas que sufrían como consecuencia de la venta de sal de contrabando, especialmente a través de la frontera con Portugal. La situación no era nueva en absoluto. Ya en 1411 tenemos noticia del pago compensatorio de $3.500 \mathrm{mrs}$. de la "moneda vieja" - anterior a la reforma monetaria llevada a cabo por Enrique III- que debía realizar el concejo de Ledesma en favor de los recaudadores reales del obispado de Salamanca por el consumo de la sal del salín de Portogal en lugar de la del salín del rey ${ }^{110}$. De nuevo, un memorial remitido a Juan

106. AGS, RGS, noviembre de 1489, f. 78 .

107. Ello permite matizar la afirmación realizada por Ladero referida a la ausencia de vestigios de la adquisición de cuotas obligatorias. M.Á. LADERO QUESADA. "La renta de la sal...”, p. 826.

108. C. RUBIO PARDOS. et al. (eds.) Libros de acuerdos del concejo Madrileño. Vol. 3. Años 1493-1497, Madrid, Ayuntamiento de Madrid, 1979, p. 123.

109. C. RUBIO PARDOS, R. SÁNCHEZ GONZÁLEZ, M.C. CAYETANO MARTÍN. (eds.) Libros de Acuerdos del Concejo Madrileño. Vol. 4. Años 1498-1501, Madrid, Ayuntamiento de Madrid, 1982, p. 142.

110. En mayo de 1411 el infante don Fernando, como regente de Juan II, ordenaba a los recaudadores y arrendadores del obispado de Salamanca no cobrar estos 3.500 mrs., después de las quejas presentadas por el concejo de Ledesma que aseguraba no haber consumido sal del salín del Portugal "en guerra nin en paz, por lo qual dizen que no son tenudos a pagar los tales maravedíes". A. MARTÍN EXPÓSITO, J.M. MONSALVO ANTÓN. Documentación Medieval del Archivo Municipal de Ledes- 
II hacia 1429 denunciaba la circulación de sal portuguesa en Castilla ${ }^{111}$, mientras que el cuaderno de 1447 ratificaba la prohibición referida a la entrada de sal de Aragón, Navarra o Portugal en los límites por los cuales debía circular la sal de Atienza, y establecía de forma específica el consumo obligatorio de esta última en ciudades como Salamanca y Ciudad Rodrigo, próximas a la frontera lusa ${ }^{112}$, lo cual es un buen indicio del incumplimiento de la normativa en función de la posibilidad que el fraude ofrecía de lograr en estas zonas el abastecimiento a un menor precio. Todo apunta a que la situación se mantuvo en los mismos términos a lo largo de los siguientes decenios, e incluso cobró auge en momentos de confrontación civil pues, tal y como reconocía en 1484 la reina...

... a cabsa de los movimientos e escándalos pasados en estos nuestros reynos acaesçidos e con el poco favor que las dichas nuestras rentas tenían en aquellos tienpos, algunas personas e conçejos en grand osadya e atrevimiento pasaron contra las dichas leyes e fueron en meter la dicha sal de fuera de los dichos nuestros reynos e en dar lugar que se metyese ${ }^{113}$.

Tras las demandas formuladas por los recaudadores de las salinas del trienio 1482-1484, Isabel I reiteraba en una pragmática dada en Córdoba el 3 de septiembre de 1484 la prohibición de introducir sal en el límite territorial asignado a las salinas de Atienza bajo pena de pérdida del producto y de las carretas, bueyes, acémilas, rocines, asnos y aparejos utilizados para su transporte además del pago de una multa de 600 mrs., cantidad minúscula que respondía al establecimiento de la ley en épocas pasadas ${ }^{114}$. Por otra parte, el mismo día también autorizaba a sus contadores mayores para que pudiesen suspender a los arrendadores $200.000 \mathrm{mrs}$. anuales en su cargo por el dapño que avían reçebido e esperavan reçebir en las dichas salinas de Atyenca por non comerse la sal d'ellas en los lugares de sus límites $^{115}$. De nuevo, entre las condiciones de arrendamiento de los años 1485-1486 figuran sendas suspensiones por otros 200.000 mrs. anuales por non guardarse las condiçiones de los límites por razón de la sal que ha entrado de Portogal ${ }^{116}$.

ma, Salamanca, Ediciones de la Diputación de Salamanca, 1986, doc. 66. Por su parte, Gonzalo González de Toro, recaudador mayor del rey en los obispados de Salamanca y Ciudad Rodrigo, recordaba en agosto de 1411 al mismo concejo de Ledesma la obligación de entregar 3.500 mrs. de la "moneda vieja” correspondientes al año 1410 "por razon del salín de Badajoz”. Ibid., doc. 68.

111. AGS, CCA, Div., leg. 4, doc. 35. Ed. M.Á. LADERO QUESADA. "La Hacienda Real...", p. 351 .

112. CSA, leyes 3 y 10 , pp. 417 y 419 .

113. Pragmática de los reyes sobre las salinas dada en Córdoba el 3 de septiembre de 1484. AGS, EMR, leg. 62-2, ff. 521-524.

114. AGS, EMR, leg. 62-2, ff. 521-524. En 1497 los arrendadores vuelven a solicitar el cumplimiento de la pragmática pues se seguía introduciendo sal desde Portugal por los obispados de Zamora, Salamanca, Ciudad Rodrigo, Coria y Plasencia.

115. AGS, EMR, leg. 36, ff. 92-94.

116. AGS, EMR, leg. 39, f. 479. Relación de cuenta de 1486 en AGS, EMR, leg. 42, f. 268. La cédula en la cual se ordenó el descuento, que también se refería a ciertas cantidades "por la sal que de las dichas salinas se sacó e sacare de lo que ovo a dar Pedro de Cogollos del año pasado de LXXXI en 
Por su parte, Gonzalo de Valencia, arrendador mayor de las salinas de Atienza durante el período 1484-1487 volvía a denunciar en 1486 la persistencia de la entrada de sal de fuera parte de las dichas salinas en sus límites y las violencias que recibían los encargados de vigilar el cumplimiento de las condiciones de venta, a pesar de las advertencias realizadas a los concejos que toleraban tal práctica, pues...

...algunas personas an salido con mano armada de las dichas çibdades y villas e logares contra las personas que tienen puestas por guardas en los dichos limites para que non entre sal en ellos de otra parte.

En respuesta a su denuncia, el 10 de marzo de 1486 los reyes comisionaban al alcalde Pedro de Valladolid, vecino de Villalar, para que acudiese a las ciudades y villas incluidas en el territorio por el cual circulaba la sal de Atienza para sustanciar las demandas formuladas ${ }^{117}$.

No obstante, los intentos por ejercer un control efectivo sobre el contrabando no cesaron, tal y como certifica un asiento incluido en las cuentas rendidas por el recaudador Juan de Álamos correspondientes a 1489 relativo al pago de $20.040 \mathrm{mrs}$. al bachiller Juan de Molina y al escribano Diego de Valera por el salario correspondiente al tiempo que emplearon en yr a hazer la pesquisa sobre el pleyto que tratava la çibdad de Salamanca con las salinas de Atiença ${ }^{118}$. Como sucede en otras circunstancias similares, resulta complicado determinar hasta qué punto las denuncias presentadas por los agentes fiscales respondían a una realidad cuantificable y objetiva, y no a un intento por aprovechar en su favor una infracción más o menos habitual de la norma. Lo cierto es que en los arrendamientos formalizados a partir de 1490 se incluyó una nueva cláusula según la cual se aceptarían las suspensiones reconocidas en años anteriores...

...salvo en lo que toca al entrar de la sal de Portogal para Salamanca e su tierra e al guiar de la sal de las salinas del duque de Medinaçeli que por esto no aya de poner nin ponga descuento alguno. E sy la dicha sal de Portogal entrare e se comiere en las otras villas e lugares del obispado de Salamanca e del obispado de Çibdad Rodrigo o en otras qualesquier, que por ello non pongan descuento alguno, salvo sy fuere con liçençia de Sus Altezas por su carta firmada de sus nonbres e por carta librada de sus contadores mayores. [E] que para el defendimiento d'ello e de las pesquisas que sobr'ello se devan fazer le sean dados los esecutores que pidieren e todas las provisiones e favores que menester oviere e çerca d'ello de justiçia se devan dar ${ }^{119}$.

que los dichos recabdadores reçibieron agravio porque se sacó en los años de su arrendamiento no se pudiendo sacar", en AGS, CCA, Div., leg. 6, doc. 23.

117. AGS, RGS, marzo de 1486, f. 172.

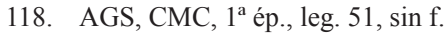

119. Condición incluida en el arrendamiento de las salinas de Atienza, Anchuelo e Imón formalizado para 1490-1496 por Ça Caro. AGS, EMR, leg. 47, ff. 321-324. La condición se repite en el arrendamiento de las salinas de los años 1492-1497 formalizado por Juan de Figueroa después de que 
A pesar de estas condiciones, que trataban de atajar por vía judicial las denuncias, los conflictos en torno a la introducción fraudulenta de sal continuaron durante toda la década de 1490. Así parecen certificarlo las constantes peticiones de nombramiento de alcaldes realizadas por los arrendadores de las salinas, amparadas en una de las cláusulas de arrendamiento de la renta que permitía a estos últimos designar cada año 4 o 5 "hombres buenos" entre los cuales el Consejo Real nombraría uno para que andase junto a los arrendadores de las salinas por las ciudades, villas y lugares de los límites para librar los pleitos, demandas y conflictos surgidos ${ }^{120}$. Por ejemplo, don Ça Caro, arrendador mayor en 1490, solicitaba a los reyes el nombramiento de dos alcaldes -uno para que estuviese en las salinas y otro itinerante que debía andar por todas las ciudades y villas de su territorio de venta- para sustanciar los pleitos que surgiesen por la venta fraudulenta de sal, a lo cual accedieron los reyes en noviembre de 1490, fecha en la cual designaban para este cometido a los continos Fernán Vázquez de Portillo, vecino de Segovia, y a Fernando de Contreras, vecino de Ávila ${ }^{121}$. De nuevo en 1495 los reyes nombraban al comendador Francisco Maldonado, vecino de Paradinas, como alcalde para que Juan de Figueroa, recaudador mayor de las salinas entre San Juan de 1491 y San Juan de 1496, pudiese pedyr e demandar la dicha renta a aquellos que cometían fraudes $^{122}$. Poco después se iniciaban diversas acciones judiciales contra Béjar y su tierra a propósito del consumo de sal procedente de Portugal y del pago del llamado derecho "del salín" que habilitaba a la villa para consumir sal blanca de cualquier procedencia, lo cual ratifica que los pagos compensatorios que ya habíamos visto en los primeros años del siglo XV para el caso de Ledesma continuaban operativos a fines de la centuria en el obispado de Salamanca ${ }^{123}$. Por otra parte, en 1497 los arrendadores volvieron a solicitar que se tuviese en cuenta la pragmática dada por la reina en 1484 pues se seguía introduciendo sal desde Portugal por los obispados de Zamora, Salamanca, Ciudad Rodrigo, Coria y Plasencia ${ }^{124}$, mientras que en una relación de los mrs. gastados por el recaudador Juan de Álamos hasta fin de agosto de 1501 para sufragar los pleitos abiertos en defensa de los derechos salineros figura una partida de 20.000 mrs. abonada al receptor Gómez de Córdoba, vecino de Valladolid, encargado de fazer la provança del pleyto de Çibdad Rodrigo $^{125}$, sin duda relacionado con la supresión hacia 1492 de la licencia de la

don Ça Caro renunciase a contentar la renta de fianzas. AGS, EMR, leg. 51, ff. 323-324; leg. 54, ff. 276-277.

120. CSA, Ley 21, p. 422.

121. AGS, RGS, noviembre de 1490, f. 93.

122. A. BARRIOS GARCÍA, A. MARTÍN EXPÓSITO. Documentación medieval de los Archivos Municipales de Béjar y Candelario, Salamanca, Ediciones de la Diputación de Salamanca, 1986, doc. 77, pp. 171-173.

123. Ibid., docs. 78 y 79, p. 173 .

124. AGS, EMR, leg. 62-2, ff. 521-524.

125. AGS, EMR, leg. 66, f. 371. 
ciudad para importar sal portuguesa, de nuevo recuperada en 1505 a cambio de la satisfacción de cierta contribución ${ }^{126}$.

\section{Evolución cuantitativa de la renta de las salinas de Atienza (1427-1510)}

Una vez explicado el régimen de explotación, venta y control del fraude, resta conocer la evolución del rendimiento fiscal de las salinas de Atienza para la Corona, cuyo análisis se puede llevar a cabo para un período que arranca en 1427, año a partir del cual conservamos de forma casi ininterrumpida la serie de precios de arrendamiento ${ }^{127}$. La práctica habitual consistía en aceptar la presentación de licitaciones por períodos amplios -habitualmente de seis años, frente a los cuatro años como máximo por los cuales se arrendaban alcabalas y tercias- quizás porque era necesario amortizar las inversiones llevadas a cabo en las explotaciones salineras y garantizar a los agentes fiscales unas garantías mínimas de continuidad que hiciesen atractivo el arrendamiento de la renta, a pesar de que durante los reinados de Juan II y Enrique IV ello supuso un descenso en el poder adquisitivo del alquiler dentro de un mismo ciclo arrendaticio como consecuencia de la devaluación experimentada por la moneda de cuenta (maravedí). La tabla que adjuntamos a continuación muestra la evolución de estos precios en maravedíes, en reales de plata al cambio oficial y en reales al cambio burgalés ${ }^{128}$, aunque hay que señalar que el precio anual que asentamos, especialmente para los reinados de Juan II y Enrique IV, se refiere a un valor teórico resultado de dividir entre los años de arrendamiento la cantidad ofrecida para la totalidad de cada período de arrendamiento. En realidad, la dificultad para poner en explotación las salinas durante el primer año de arrendamiento llevó a adoptar una particular práctica según la cual la Corona solía aceptar un descuento del precio obligado durante el primer año, repartido entre los restantes. Así, en el arrendamiento formalizado por don Çulemán Abenaex, vecino de Ávila, para el sexenio 1435-1440 se acordó el pago de 4.038.995 mrs. de forma global para todo el período, de forma que a cada año le hubiera correspondido teóricamente el abono de $673.165 \mathrm{mrs}$. No obstante, según quedó establecido en las condiciones de arrendamiento, el primer año se debían abaxar o deducir del cargo 273.165 mrs., cantidad que sería cargada en el

126. J.L. MARTÍN MARTÍN. "La frontera hispano-portuguesa en la guerra, en la paz y el comercio", en A.M. Carabias Torres (ed.), Las relaciones entre Portugal y Castilla en la época de los descubrimientos y la expansión colonial, Salamanca, Ediciones de la Universidad de Salamanca, 1996, p. 44.

127. Algunos datos en relación al rendimiento de las salinas durante el siglo XV ya fueron presentados en el trabajo de M.Á. LADERO QUESADA. "La Hacienda Real...”, p. 172.

128. Los cambios monetarios oficiales en M.Á. LADERO QUESADA. "La política monetaria en la Corona de Castilla (1369-1497)", en id., La Hacienda Real de Castilla (1369-1504)..., pp. 778804. Equivalencias monetarias del real en Burgos a partir de A. MACKAY. Moneda, precios y política en la Castilla del siglo XV, Granada, Editorial Universidad de Granada, 2006, apéndice B, pp. 778-804. Para el período 1500-1504 se tiene en cuenta el cambio oficial. 
precio de los años 1436-1438 por tercios. De esta forma, el arrendador se comprometía a abonar en 1435400.000 mrs., en 1436-1438 764.220 mrs. anuales, y en 1439-1440 673.165 mrs. anuales ${ }^{129}$. La práctica se mantuvo en los arrendamientos formalizados durante los reinados de Juan II y Enrique IV ${ }^{130}$, aunque desapareció durante la época de los Reyes Católicos sin que conozcamos el motivo.

Tabla 1. Precio de arrendamiento de las salinas de Atienza (1427-1510) 131

\begin{tabular}{|c|r|r|r|r|r|r|}
\hline \multirow{2}{*}{ Año } & \multicolumn{2}{|c|}{ Mrs. } & \multicolumn{2}{c|}{$\begin{array}{c}\text { Reales } \\
\text { (cambio oficial) }\end{array}$} & \multicolumn{2}{c|}{$\begin{array}{c}\text { Reales } \\
\text { (cambio de Burgos) }\end{array}$} \\
\cline { 2 - 8 } & \multicolumn{1}{|c|}{ Precio } & Índice & \multicolumn{1}{c|}{ Precio } & \multicolumn{1}{c|}{ Índice } & \multicolumn{1}{c|}{ Precio } & \multicolumn{1}{c|}{ Índice } \\
\hline 1427 & 680.177 & 100 & 85.022 & 100 & 97.168 & 100 \\
\hline 1428 & 680.177 & 100 & 85.022 & 100 & 97.168 & 100 \\
\hline 1429 & 680.177 & 100 & 85.022 & 100 & 97.168 & 100 \\
\hline 1430 & 680.177 & 100 & 85.022 & 100 & 97.168 & 100 \\
\hline 1431 & 700.577 & 103 & 87.572 & 103 & 100.082 & 103 \\
\hline 1432 & 700.577 & 103 & 87.572 & 103 & 100.082 & 103 \\
\hline 1433 & 700.577 & 103 & 87.572 & 103 & 100.082 & 103 \\
\hline 1434 & 700.577 & 103 & 87.572 & 103 & 96.631 & 99 \\
\hline 1435 & 673.165 & 99 & 84.146 & 99 & 84.146 & 87 \\
\hline 1436 & 673.165 & 99 & 84.146 & 99 & 84.146 & 87 \\
\hline 1437 & 673.165 & 99 & 84.146 & 99 & 76.933 & 79 \\
\hline 1438 & 673.165 & 99 & 79.196 & 93 & 76.933 & 79 \\
\hline 1439 & 673.165 & 99 & 79.196 & 93 & 76.933 & 79 \\
\hline 1440 & 673.165 & 99 & 67.317 & 79 & 67.317 & 69 \\
\hline 1441 & 716.000 & 105 & 71.600 & 84 & 73.436 & 76 \\
\hline 1442 & 716.000 & 105 & 89.500 & 105 & 75.368 & 78 \\
\hline
\end{tabular}

129. AGS, EMR, leg. 2, f. 1v; leg. 2, ff. 97v-98r.

130. Para el arrendamiento de 1447-1452 ver AGS, EMR, leg. 2, ff. 394v-395r. Según las condiciones de arrendamiento de los años 1456-1461 el precio anual de arrendamiento quedó establecido en $1.200 .000 \mathrm{mrs}$. No obstante el primer año los arrendadores solo pagarían $400.000 \mathrm{mrs}$. Los $800.000 \mathrm{mrs}$. de la baja se cargaron en los tres años siguientes de forma que en 1457-1459 el total obligado ascendió a 1.466 .666 mrs. anuales. Durante el bienio $1460-1461$ se pagaron los $1.200 .000 \mathrm{mrs}$. anuales comprometidos inicialmente. AGS, EMR, leg. 1, ff. 305.

131. Datos de 1427-1430 en AGS, EMR, leg. 1, ff. 219-224. Datos de 1431-1434 en AGS, EMR, leg. 1, ff. 276-281. Datos de 1435-1440 en AGS, EMR, leg. 2, ff. 1v y 97v-98r. Datos de 1441-1446 en AGS, EMR, leg. 2, f. 350r. Datos de 1447-1451 en AGS, EMR, leg. 2, ff. 394v-395r. Datos de 14521454 en AGS, EMR, leg. 3, ff. 250-253. Datos de 1456-1461 en AGS, EMR, leg. 1, f. 305; leg. 5-2, ff. 566-567; leg. 8-1, ff. 377-380. Datos de 1462-1465 en AGS, EMR, leg. 28-2, f. 11; leg. 13, f. 85. Datos de 1466-1471 en AGS, EMR, leg. 14, f. 148; leg. 15, ff. 140-142. 


\begin{tabular}{|c|c|c|c|c|c|c|}
\hline \multirow[t]{2}{*}{ Año } & \multicolumn{2}{|c|}{ Mrs. } & \multicolumn{2}{|c|}{$\begin{array}{c}\text { Reales } \\
\text { (cambio oficial) }\end{array}$} & \multicolumn{2}{|c|}{$\begin{array}{c}\text { Reales } \\
\text { (cambio de Burgos) }\end{array}$} \\
\hline & Precio & Índice & Precio & Índice & Precio & Índice \\
\hline 1443 & 716.000 & 105 & 89.500 & 105 & 68.190 & 70 \\
\hline 1444 & 716.000 & 105 & 89.500 & 105 & 66.605 & 69 \\
\hline 1445 & 716.000 & 105 & 89.500 & 105 & 68.190 & 70 \\
\hline 1446 & 716.000 & 105 & 89.500 & 105 & 62.261 & 64 \\
\hline 1447 & 1.035 .230 & 152 & 129.404 & 152 & 85.064 & 88 \\
\hline 1448 & 1.035 .230 & 152 & 129.404 & 152 & 81.707 & 84 \\
\hline 1449 & 1.035 .230 & 152 & 129.404 & 152 & 79.633 & 82 \\
\hline 1450 & 1.035 .230 & 152 & 129.404 & 152 & 79.633 & 82 \\
\hline 1451 & 1.035 .230 & 152 & 129.404 & 152 & 71.395 & 73 \\
\hline 1452 & 975.230 & 143 & 121.904 & 143 & 67.257 & 69 \\
\hline 1453 & 975.230 & 143 & 121.904 & 143 & 67.257 & 69 \\
\hline 1454 & 975.230 & 143 & 121.904 & 143 & 67.257 & 69 \\
\hline 1455 & 975.230 & 143 & 60.952 & 72 & 69.659 & 72 \\
\hline 1456 & 1.200 .000 & 176 & 75.000 & 88 & 82.759 & 85 \\
\hline 1457 & 1.200 .000 & 176 & 75.000 & 88 & 80.000 & 82 \\
\hline 1458 & 1.200 .000 & 176 & 60.000 & 71 & 66.667 & 69 \\
\hline 1459 & 1.200 .000 & 176 & 60.000 & 71 & 61.538 & 63 \\
\hline 1460 & 1.200 .000 & 176 & 60.000 & 71 & 64.865 & 67 \\
\hline 1461 & 1.200 .000 & 176 & 60.000 & 71 & 66.667 & 69 \\
\hline 1462 & 1.580 .000 & 232 & 98.750 & 116 & 98.750 & 102 \\
\hline 1463 & 1.580 .000 & 232 & 98.750 & 116 & 98.750 & 102 \\
\hline 1464 & 1.580 .000 & 232 & 98.750 & 116 & 89.014 & 92 \\
\hline 1465 & 1.580 .000 & 232 & 79.000 & 93 & 92.941 & 96 \\
\hline 1466 & 1.410 .364 & 207 & 70.518 & 83 & 75.542 & 78 \\
\hline 1467 & 1.380 .184 & 203 & 69.009 & 81 & 71.698 & 74 \\
\hline 1468 & 1.380 .184 & 203 & 69.009 & 81 & 67.326 & 69 \\
\hline 1469 & 1.380 .184 & 203 & 69.009 & 81 & 72.641 & 75 \\
\hline 1470 & 1.380 .184 & 203 & 69.009 & 81 & 49.292 & 51 \\
\hline 1471 & 1.380 .184 & 203 & 69.009 & 81 & 51.596 & 53 \\
\hline $1472-80$ & - & - & - & - & - & - \\
\hline 1481 & 1.862 .706 & 274 & 60.087 & 71 & 60.087 & 62 \\
\hline 1482 & 1.601 .500 & 235 & 51.661 & 61 & 51.661 & 53 \\
\hline 1483 & 1.601 .500 & 235 & 51.661 & 61 & 51.661 & 53 \\
\hline 1484 & 1.601 .500 & 235 & 51.661 & 61 & 51.661 & 53 \\
\hline
\end{tabular}




\begin{tabular}{|r|r|r|r|r|r|r|}
\hline \multirow{2}{*}{ Año } & \multicolumn{2}{|c|}{ Mrs. } & \multicolumn{2}{c|}{$\begin{array}{c}\text { Reales } \\
\text { (cambio oficial) }\end{array}$} & \multicolumn{2}{c|}{$\begin{array}{c}\text { Reales } \\
\text { (cambio de Burgos) }\end{array}$} \\
\cline { 2 - 8 } & \multicolumn{1}{c|}{ Precio } & Índice & \multicolumn{1}{c|}{ Precio } & \multicolumn{1}{c|}{ Índice } & \multicolumn{1}{c|}{ Precio } & \multicolumn{1}{c|}{ Índice } \\
\hline 1485 & 1.601 .500 & 235 & 51.661 & 61 & 51.661 & 53 \\
\hline 1486 & 1.601 .500 & 235 & 51.661 & 61 & 51.661 & 53 \\
\hline 1487 & 1.601 .500 & 235 & 51.661 & 61 & 51.661 & 53 \\
\hline 1488 & 1.701 .500 & 250 & 54.887 & 65 & 54.887 & 56 \\
\hline 1489 & 1.701 .500 & 250 & 54.887 & 65 & 54.887 & 56 \\
\hline 1490 & 2.503 .000 & 368 & 80.742 & 95 & 80.742 & 83 \\
\hline 1491 & 2.301 .500 & 338 & 74.242 & 87 & 74.242 & 76 \\
\hline 1492 & 2.301 .500 & 338 & 74.242 & 87 & 74.242 & 76 \\
\hline 1493 & 2.301 .500 & 338 & 74.242 & 87 & 74.242 & 76 \\
\hline 1494 & 2.301 .500 & 338 & 74.242 & 87 & 74.242 & 76 \\
\hline 1495 & 2.301 .500 & 338 & 74.242 & 87 & 74.242 & 76 \\
\hline 1496 & 2.501 .500 & 368 & 80.694 & 95 & 80.694 & 83 \\
\hline 1497 & 2.501 .500 & 368 & 73.574 & 87 & 73.574 & 76 \\
\hline 1498 & 3.301 .500 & 485 & 97.103 & 114 & 97.103 & 100 \\
\hline 1499 & 3.301 .500 & 485 & 97.103 & 114 & 97.103 & 100 \\
\hline 1500 & 3.301 .500 & 485 & 97.103 & 114 & 97.103 & 100 \\
\hline 1501 & 3.301 .500 & 485 & 97.103 & 114 & 97.103 & 100 \\
\hline 1502 & 3.301 .500 & 485 & 97.103 & 114 & 97.103 & 100 \\
\hline 1503 & 3.301 .500 & 485 & 97.103 & 114 & 97.103 & 100 \\
\hline 1504 & 3.861 .500 & 568 & 113.574 & 134 & 113.574 & 117 \\
\hline 1505 & 3.861 .500 & 568 & 113.574 & 134 & 113.574 & 117 \\
\hline 1506 & 3.861 .500 & 568 & 113.574 & 134 & 113.574 & 117 \\
\hline 1507 & 3.861 .500 & 568 & 113.574 & 134 & 113.574 & 117 \\
\hline 1508 & 3.861 .500 & 568 & 113.574 & 134 & 113.574 & 117 \\
\hline 1509 & 3.861 .500 & 568 & 113.574 & 134 & 113.574 & 117 \\
\hline 1510 & 3.861 .500 & 568 & 113.574 & 134 & 113.574 & 117 \\
\hline
\end{tabular}




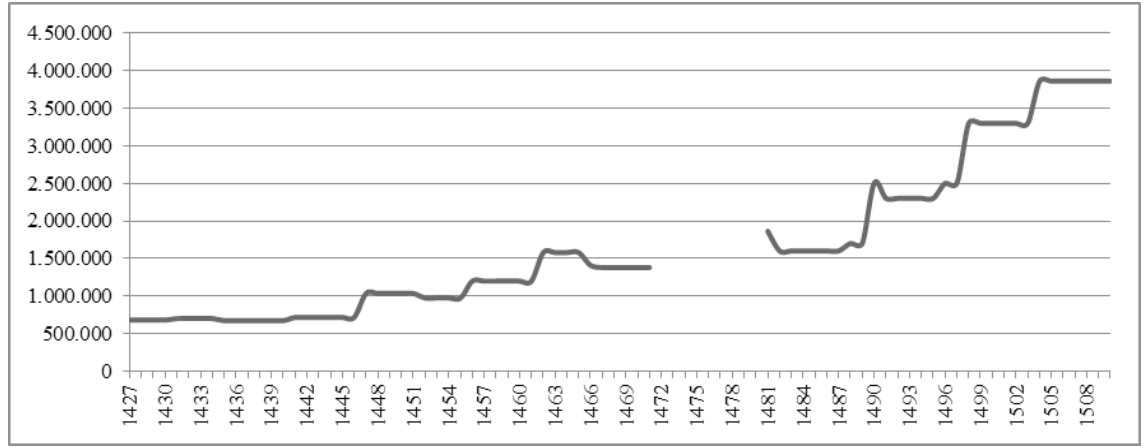

Ilustración 4. Evolución en mrs. del precio de arrendamiento de las salinas de Atienza (1427-1510)

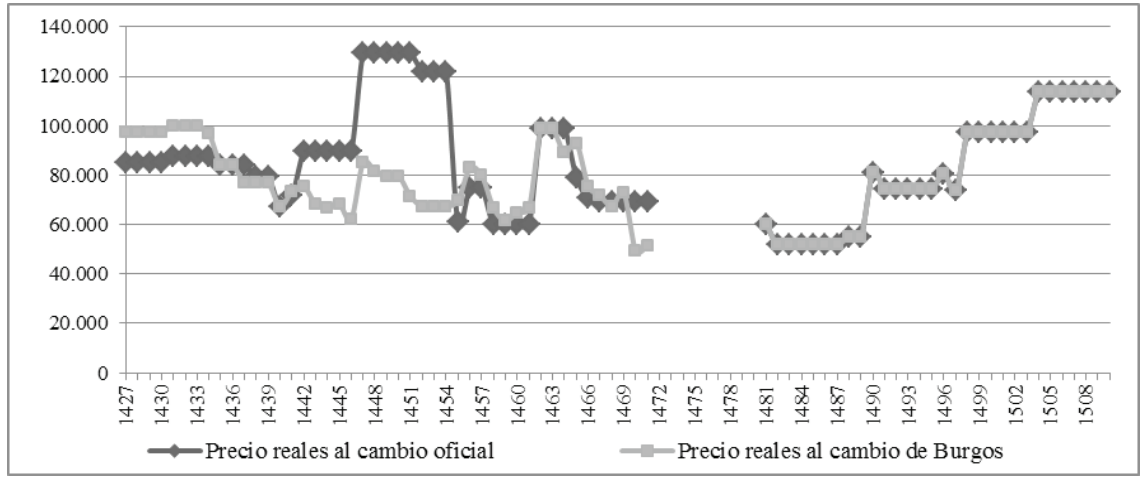

Ilustración 5. Evolución en reales del precio de arrendamiento de las salinas de Atienza (1427-1510)

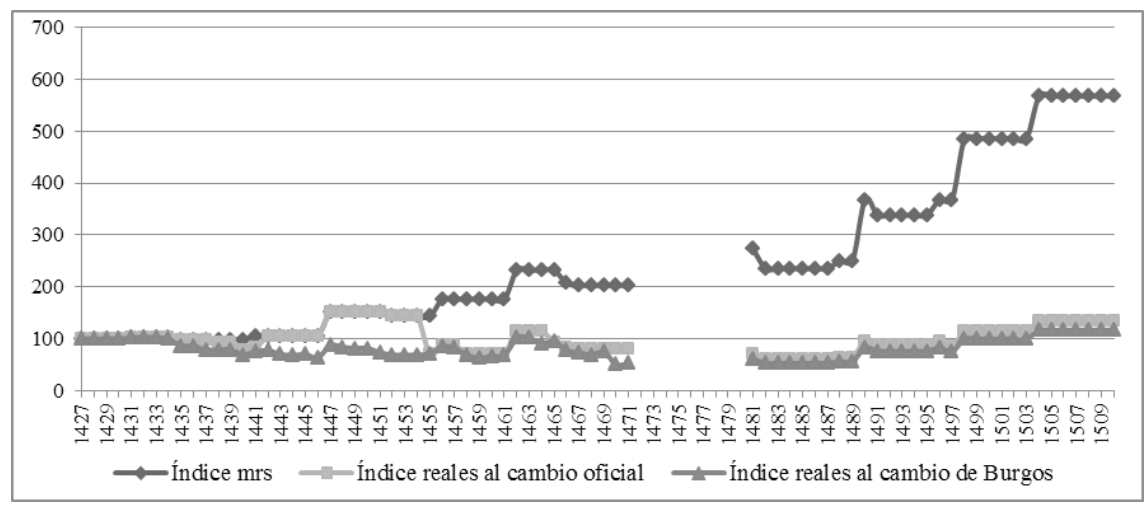

Ilustración 6. Evolución en números índice del precio de arrendamiento de las salinas de Atienza (1427-1510). $1427=$ Índice 100 
Una ojeada a los precios nominales, en maravedíes, permite apreciar el enorme crecimiento experimentado entre 1427 y 1504 por la renta, de forma que entre ambas fechas las cuantías obligadas anualmente se habían multiplicado casi por seis (se pasó de los 680.177 mrs. anuales del cuatrienio 1427-1430 a los 3.861 .500 mrs. anuales del período 1504-1510). Sin embargo, los precios deflactados en reales al cambio oficial y al cambio burgalés experimentaron una evolución muy diferente. Entre 1435 y 1440 los valores en reales al cambio de Burgos sufrieron un descenso del $30 \%$ en relación a los precios de 1427-1430, más matizado si acudimos a las cifras en reales al cambio oficial. Durante las décadas de 1440, 1450 y 1460 los precios en reales al cambio de Burgos se mantuvieron entre los índices 70-90, con grandes fluctuaciones, lo cual implica considerar que en la renta de la sal la caída en el precio fue algo más moderada que la observada en el mismo período en otras rentas regias ordinarias como las alcabalas y tercias ${ }^{132}$, llegándose incluso a superar el índice 100 durante el bienio 1462-1463 como consecuencia de la revaluación del maravedí en relación a las monedas de plata y oro decretada en $1462^{133}$. No obstante, a partir de 1466 se observa una caída drástica en el precio hasta el índice 51 de 1470, situación motivada por la nueva devaluación del maravedí operada durante la época de caos monetario que marcó la segunda mitad del reinado de Enrique IV, y quizás por la enajenación de las salinas de Imón realizada en favor del alcaide de Atienza Pedro de Almazán en 1466, año en el cual se formalizó el último arrendamiento del reinado enriqueño del cual tenemos constancia. Los precios en reales calculados a partir de 1481, tras un vacío de noticias durante una década, permiten apreciar la recuperación operada en la renta, especialmente a partir de 1490. El motivo no es otro que la restauración del control de la Corona sobre las importantes salinas de Imón, cedidas como vimos de por vida al alcaide de Atienza Garci Bravo de Lagunas hacia 1477 y arrendadas de nuevo junto a las restantes salinas atencinas desde 1490, una vez fallecido su antiguo beneficiario $^{134}$. Ello se tradujo en un incremento en los precios, que recuperaron durante el período 1498-1503 el índice 100 del cuatrienio 1427-1430 y lo incrementaron notablemente a partir de 1504 (índice 117).

Por otra parte, no parece que las variaciones apuntadas a lo largo de todo el arco temporal analizado respondan a alteraciones importante en los niveles de producción, sino a otras circunstancias relacionadas con el sistema de gestión (quiebras de compañías y renuncias a contentar la renta de fianzas) y la venta de la sal (conflictividad política, incremento del contrabando, política de enajenaciones de salinas en forma de merced, aprovechamiento fraudulento de pozos salados por parte de particulares...). En este sentido, todo apunta a que las medidas tomadas

132. Sobre esta cuestión ver P. ORTEGO RICO. Hacienda, poder real y sociedad en Toledo y su Reino (siglo XV-principios del XVI). Tesis doctoral inédita. Departamento de Historia Medieval, Universidad Complutense de Madrid, 2013, pp. 310-318.

133. M.Á. LADERO QUESADA. "Moneda y tasa de precios en 1462: Un episodio ignorado en la política económica de Enrique IV de Castilla”, Moneda y Crédito, 129 (1974), pp. 91-115.

134. Así se especifica en el arrendamiento de 1490 y en la relación de cuenta dada por los contadores a don Ça Caro para dicho año. AGS, EMR, leg. 49, ff. 359-360. 
por los Reyes Católicos contribuyeron, junto a la recuperación del control de la Corona sobre las mencionadas salinas de Imón, a terminar con la situación de deterioro en la cual se encontraba la renta a comienzos del reinado, consolidando el arrendamiento de las salinas de Atienza como un recurso fiscal saneado.

\section{BiBLIOGRAFÍA}

ÁlVAREZ PALENZUELA, V.Á. Monasterios cistercienses en Castilla (siglos XII-XIII), Valladolid, Universidad de Valladolid, 1978.

ASSO Y DEL RÍO, I.J., DE MANUEL Y RODRÍGUEZ, M. El ordenamiento de leyes que D. Alfonso XI hizo en las Cortes de Alcalá de Henares el año de mil trescientos y quarenta y ocho, Madrid, Joaquín Ibarra, 1774.

BALlESTEROS BERETTA, A. Alfonso X el Sabio, Barcelona, Salvat, 1963.

BARRIOS GARCÍA, Á., MARTÍN EXPÓSITO, A. Documentación medieval de los Archivos Municipales de Béjar y Candelario, Salamanca, Ediciones de la Diputación de Salamanca, 1986.

BENAVIDES, A. Memorias de D. Fernando IV de Castilla, Madrid, Imprenta de José Rodríguez, 1860, vol. II.

CARRETERO ZAMORA, J.M., ALONSO GARCÍA, D. Hacienda y negocio financiero en tiempos de Isabel la Católica: el libro de hacienda de 1503, Madrid, Editorial Complutense, 2003.

CHEVALIER, B. "Aux origines de la Ferme. Les villes et le monopole d'approvisionnement des greniers à sel (fin XIVe-milieu XVIe siècle)", en J.-C. Hocquet (ed.), Le roi, le marchand et le sel, Lille, Presses Universitaires de Lille, 1987, pp. 133-150.

CORTÉS RUIZ, M.E. Articulación jurisdiccional y estructura socioeconómica en la comarca de Molina de Aragón a lo largo de la baja Edad Media. Madrid, Universidad Complutense de Madrid, 2003.

CRUZ GARCÍA, Ó. "Norias de tradición mudéjar en las salinas de Imón (Guadalajara)", Revista de Folklore, 107 (1989), pp. 147-160.

ESPEJO, C. "La renta de las salinas hasta la muerte de Felipe II", Revista de Archivos, Bibliotecas y museos, 38 (1918), pp. 47-63 y 220-233; 39 (1918), pp. 37-53; y 40 (1919), pp. 91-114.

FRANCO SILVA, A. "La fortuna del Adelantado Mayor de Castilla Gómez Manrique", en id., La fortuna y el poder. Estudios sobre las bases económicas de la aristocracia castellana (S.XIV-XV), Cádiz, Universidad de Cádiz, Servicio de Publicaciones, 1996. pp. 355-378.

GARCÍA-CONTRERAS RUIZ, G. "Territorio y explotación de la sal en el valle del Salado (Guadalajara) en época andalusí”, @rqueología y Territorio, 6 (2009), pp. 211-224.

GARCÍA-SOTO MATEOS, E., FERRERO ROS, S. "Excavaciones en las salinas de San Juan: Saelices de La Sal, Guadalajara”, Boletín de la Asociación de Amigos del Museo de Guadalajara, 1 (2006), pp. 81-112. 
GONZÁLEZ CRESPO, E. Colección documental de Alfonso XI, Madrid, Universidad Complutense de Madrid, 1985.

GONZÁleZ GONZÁLEZ, J. El Reino de Castilla en la época de Alfonso VIII, Madrid, CSIC, 1960, vol. III.

- Reinado y diplomas de Fernando III. Vol. II. Diplomas (1217-1232), Córdoba, Publicaciones del Monte de Piedad y Caja de Ahorros de Córdoba, 1983.

HERNÁNDEZ, F.J. Las rentas del rey. Sociedad y fisco en el reino castellano del siglo XIII, Madrid, Fundación Ramón Areces, 1994.

LADERO QUESADA, M.Á. "Moneda y tasa de precios en 1462: Un episodio ignorado en la política económica de Enrique IV de Castilla", Moneda y Crédito, 129 (1974), pp. 91-115.

—. "La renta de la sal en la Corona de Castilla (Siglos XIII-XVI)", en Homenaje al profesor Juan Torres Fontes, Murcia, Universidad de Murcia, 1987, vol. I, pp. 821-838.

- Legislación hacendística de la corona de Castilla en la Baja Edad Media, Madrid, Real Academia de la Historia, 1999.

—. "La Hacienda Real de Castilla en el siglo XV", en id., La Hacienda Real de Castilla (1369-1504), Madrid, Real Academia de la Historia, 2009, pp. 1-399. Reed. La Hacienda Real de Castilla en el siglo XV, La Laguna, Publicaciones de la Universidad, 1973.

—. "La política monetaria en la Corona de Castilla (1369-1497)", en id., La Hacienda Real de Castilla (1369-1504), Madrid, Real Academia de la Historia, 2009, pp. 763-808.

-. Fiscalidad y poder real en Castilla (1252-1369), Madrid, Real Academia de la Historia, 2011 [ $2^{\mathrm{a}}$ ed.].

Las Siete Partidas del rey don Alfonso el Sabio, Madrid, Imprenta Real, 1807.

LAYNA SERRANO, F. Historia de Guadalajara y sus Mendozas en los siglos XV y XVI, Guadalajara, Aache, 1993, vol. I.

LÓPEZ CASTILLO, S. "El ordenamiento jurídico del comercio de la sal y Salinas de Añana (Álava)", Anuario de Estudios Medievales, 14 (1984), pp. 441-466.

LÓPEZ GÓMEZ, A. "Salinas de la comarca de Imón (Guadalajara)", Estudios Geográficos, vol. 31, n 120 (1970), pp. 371-394.

MACKAY, A. Moneda, precios y política en la Castilla del siglo XV, Granada, Editorial Universidad de Granada, 2006.

MALPICA CUELLO, A. "Análisis de la salinas medievales desde la arqueología del paisaje”, en MORÈRE MOLINERO, N.E. (coord.) Las salinas y la sal de interior en la historia: economía, medio ambiente y sociedad, Madrid, Universidad Rey Juan Carlos-Dykinson, 2007, vol. 1, pp. 469-499.

-, GARCÍA-CONTRERAS RUIZ, G. “Asentamientos y explotación de la sal en el valle del Salado y la zona de Sigüenza en época altomedieval”, En la España Medieval, 32 (2009), pp. 295-324.

-, ANTONIO GONZÁLEZ ALCANTUD, J.A. (coords.) La sal, del gusto alimentario al arrendamiento de salinas, Granada, Junta de Andalucía-Consejería de Cultura, 1997. 
MANUEL, J. Libro de la caza, J.M. Blecua (ed.), Madrid, Gredos, 1981.

MARTÍN EXPÓSITO, A., MONSALVO ANTÓN, J.M. Documentación Medieval del Archivo Municipal de Ledesma, Salamanca, Ediciones de la Diputación de Salamanca, 1986.

MARTÍNEZ GÓMEZ-GORDO, J.A. "Donaciones reales a la iglesia seguntina con los diezmos de las Salinas de Imón”, Anales seguntinos, 22 (2006), pp. 7-12.

MARTÍN MARTÍN, J.L. "La frontera hispano-portuguesa en la guerra, en la paz y el comercio", en Ana María Carabias Torres (ed.), Las relaciones entre Portugal y Castilla en la época de los descubrimientos y la expansión colonial, Salamanca, Ediciones de la Universidad de Salamanca, 1996, pp. 29-52.

MINGUELLA Y ARNEDO, T. Historia de la diócesis de Sigüenza y sus obispos, Madrid, Imprenta de la Revista de Archivos, Bibliotecas y Museos, 1912, vol. 1.

MORÈRE MOLINERO, N.E. "L'exploitation romaine du sel dans la region de Sigüenza", Gerión, 3 (1991), pp. 223-236.

—. "La sal en el desarrollo histórico de Sigüenza. Los primeros siglos", en N Nuria Elisa Morère Molinero (coord.), Las salinas y la sal de interior en la historia: economía, medio ambiente y sociedad, Madrid, Universidad Rey Juan Carlos-Dykinson, 2007, vol. 1, pp. 3-31.

ORTEGO RICO, P. Hacienda, poder real y sociedad en Toledo y su Reino (siglo $X V$-principios del XVI). Tesis doctoral inédita. Departamento de Historia Medieval, Universidad Complutense de Madrid, 2013.

PARDO RODRÍGUEZ, M.L. Documentación del condado de Medinaceli (13681454), Soria, Diputación de Soria, 1993.

PASTOR DE TOGNERI, R. "La sal en Castilla y León. Un problema de alimentación y del trabajo y una política fiscal (siglos X-XIII)", Cuadernos de Historia de España, XXXVII-XXXVIII (1963), pp. 42-85.

PÉREZ BUSTAMANTE, R. El marqués de Santillana. Biografía y documentación, Santillana del Mar, Taurus, 1983.

PUlGAR, F. del. Crónica de los Reyes Católicos, J.M. Carriazo (ed), Madrid, Espasa-Calpe, 1943, vol. I.

RUBIO PARDOS, C. et al. (eds.) Libros de acuerdos del concejo Madrileño. Vol. 3. Años 1493-1497, Madrid, Ayuntamiento de Madrid, 1979.

—, SÁNCHEZ GONZÁLEZ, R., CAYETANO MARTÍN, M. del C. (eds.) Libros de Acuerdos del Concejo Madrileño. Vol. 4. Años 1498-1501, Madrid, Ayuntamiento de Madrid, 1982.

SÁNCHEZ BENITO, J.M. Las tierras de Cuenca y Huete en el siglo XV. Historia económica, Cuenca, Servicio de Publicaciones de la Universidad de CastillaLa Mancha, 1994.

SANCHO IZQUIERDO, M. El Fuero de Molina de Aragón, Madrid, Victoriano Suarez, 1916.

TALAVERA COSTA, J. "La sal en la comarca de la Sigüenza arévaca: ¿Riqueza natural-riqueza social?”, en Nuria Elisa Morère Molinero (coord.), Las salinas 
y la sal de interior en la historia: economía, medio ambiente y sociedad, Madrid, Universidad Rey Juan Carlos-Dykinson, 2007, vol. 1, pp. 241-262.

Fecha de recepción del artículo: septiembre 2013

Fecha de aceptación y versión final: octubre 2013 
